Revision 0

Keywords: waste tank, Hanford Site, elutriation

Retention: Permanent

\title{
In-Tank Elutriation Test Report and Independent Assessment
}

H. H. Burns, D. J. Adamson,

Z. H. Qureshi and T. J. Steeper

March 2011

Savannah River National Laboratory

Savannah River Nuclear Solutions

Aiken, SC 29808

Prepared for the U.S. Department of Energy under contract number DE-AC09-08SR22470.

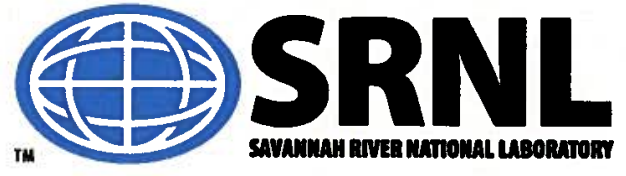


SRNL-STI-2011-00227

Revision 0

\section{DISCLAIMER}

This work was prepared under an agreement with and funded by the U.S. Government. Neither the U.S. Government or its employees, nor any of its contractors, subcontractors or their employees, makes any express or implied:

1. warranty or assumes any legal liability for the accuracy, completeness, or for the use or results of such use of any information, product, or process disclosed; or

2. representation that such use or results of such use would not infringe privately owned rights; or

3. endorsement or recommendation of any specifically identified commercial product, process, or service.

Any views and opinions of authors expressed in this work do not necessarily state or reflect those of the United States Government, or its contractors, or subcontractors.

\section{Printed in the United States of America \\ Prepared for \\ U.S. Department of Energy}




\section{REVIEWS AND APPROVALS}

AUTHORS:

H. H. Burns, E \& CPT Research Programs

Date

D. J. Adamson, Process Engineering Technology

Date

Z. H. Qureshi, Process Engineering Technology

Date

T. J. Steeper, Process Engineering Technology

Date

TECHNICAL REVIEW:

R. A. Leishear, Process Engineering Technology

Date

\section{APPROVAL:}

B. J. Giddings, Manager

Date

Process Engineering Technology

S.L. Marra, Manager

Date

Environmental \& Chemical Process Technology Research Programs 


\section{ACKNOWLEDGEMENTS}

This program was funded through Department of Energy EM-31. 
SRNL-STI-2011-00227

Revision 0

\section{EXECUTIVE SUMMARY}

The Department of Energy (DOE) Office of Environmental Management (EM) funded Technology Development and Deployment (TDD) to solve technical problems associated with waste tank closure for sites such as Hanford Site and Savannah River Site (SRS). One of the tasks supported by this funding at Savannah River National Laboratory (SRNL) and Pacific Northwest Laboratory (PNNL) was In-Tank Elutriation. Elutriation is the process whereby physical separation occurs based on particle size and density [Kirk-Othmer, 2006].

This report satisfies the first phase of Task WP-1.3.1.1 In-Tank Elutriation, which is to assess the feasibility of this method of separation in waste tanks at Hanford Site and SRS. This report includes an analysis of scoping tests performed in the Engineering Development Laboratory of SRNL, analysis of Hanford's inadvertent elutriation, the viability of separation methods such as elutriation and hydrocyclones and recommendations for a path forward.

This report will demonstrate that the retrieval of Hanford salt waste tank S-112 very successfully decreased the tank's inventories of radionuclides. Analyses of samples collected from the tank showed that concentrations of the major radionuclides, Cs-137 and Sr-90, were decreased by factors of 250 and 6 and their total curie tank inventories decreased by factors of 60,000 and 2000 . The total tank curie loading decreased from $300,000 \mathrm{Ci}$ to $55 \mathrm{Ci}$. The remaining heel was nearly all innocuous gibbsite, $\mathrm{Al}(\mathrm{OH})_{3}$. However, in the process of tank retrieval approximately $85 \%$ of the tank gibbsite was also removed. Significant amounts of money and processing time could be saved if more gibbsite could be left in tanks while still removing nearly all of the radionuclides.

There were factors which helped to make the elutriation of Tank S-112 successful which would not necessarily be present in all salt tanks.

1. The gibbsite particles in the tank were surprisingly large, as much as $200 \mu \mathrm{m}$. The gibbsite crystals had probably grown in size over a period of decades.

2. The radionuclides were apparently either in the form of soluble compounds, like cesium, or micrometer sized particles of actinide oxides or hydroxides.

3. After the initial tank retrieval the tank contained cobble which is not conducive to elutriation. Only after the tank contents were treated with thousands of gallons of 50 $w t \%$ caustic, were the solids converted to sand which is compatible with elutriation.

Discussions between SRNL and PNNL resulted in plans to test elutriation in two phases; in Phase 1 particles would be separated by differences in settling velocity in an existing scaled tank with its associated hardware and in Phase 2 additional hardware, such as a hydrocyclone, would be added downstream to separate slow settling particles from liquid. Phase 1 of intank elutriation was tested for Proof of Principle in the Engineering Development Laboratory of SRNL in a 41 " diameter, 87 gallon tank. The tank had been previously used as a 1/22 scale model of Hanford Waste Tank AY-102. The objective of the testing was to determine which tank operating parameters achieved the best separation between fast- and slow-settling particles.

For Phase 1 testing a simulated waste tank supernatant, slow-settling particles and fastsettling particles were loaded to the scaled tank. Because this was a Proof of Principle test, readily available solids particles were used that represented fast-settling and slow-settling particles. The tank contents were agitated using rotating mixer jet pumps (MJP) which suspended solids while liquid and solids were drawn out of the tank with a suction tube. The 
goal was to determine the optimum hydraulic operating conditions to achieve clean separation in which the residual solids in the tank were nearly all fast-settling particles and the solids transferred out of the tank were nearly all slow-settling particles. Tests were conducted at different pump jet velocities, suction tube diameters and suction tube elevations. Testing revealed that the most important variable was jet velocity which translates to a downstream fluid velocity in the vicinity of the suction tube which can suspend particles and potentially allow their removal from the tank. The optimum jet velocity in the vicinity of the suction tube was between 1.5 and $2 \mathrm{ft} / \mathrm{s}(4-5 \mathrm{gpm})$. During testing at lower velocities a significant amount of slow-settling particles remained in the tank. At higher velocities a significant amount of fast-settling particles were elutriated from the tank. It should be noted that this range of velocities is appropriate for this particular geometry and particles.

However, the principle of In-Tank Elutriation was proved.

In-tank elutriation has the potential to save much money in tank closure. However, more work, both analytical and experimental, must be done before an improved version of the process could be applied to actual waste tanks. It is recommended that testing with more prototypic simulants be conducted. Also, scale-up criteria for elutriation and the resulting size of pilot scale test equipment require investigation during future research. In addition, it is recommended that the use of hydrocyclones be pursued in Phase 2 testing. Hydrocyclones are a precise and efficient separation tool that are frequently used in industry. 


\section{TABLE OF CONTENTS}

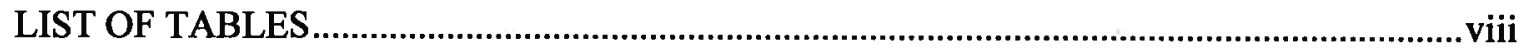

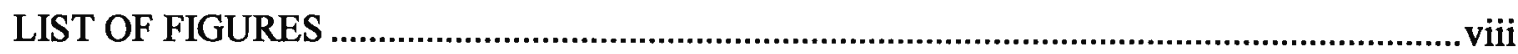

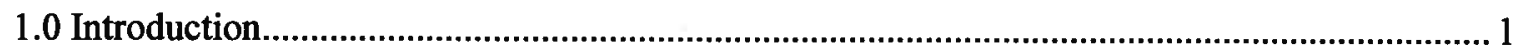

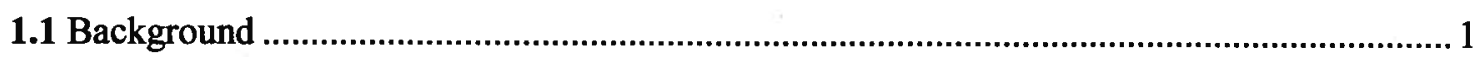

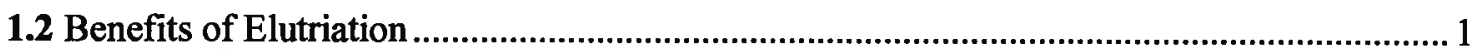

2.0 Analysis of Tank S-112 Elutriation -Independent Assessment.......................................... 1

2.1 Description of Tank S-112 Retrieval and Inadvertent Elutriation........................................ 1

2.2 Chemical Analysis of Tank S-112 Contents Before and After Retrieval.............................. 3

2.3 Evaluation of Hanford's Inadvertent Elutriation ............................................................. 4

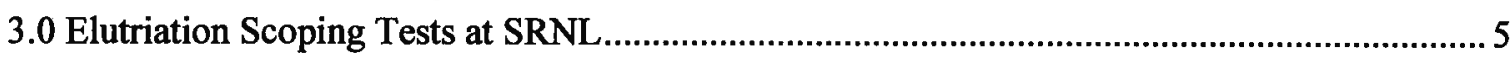

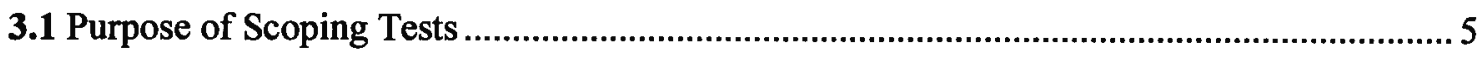

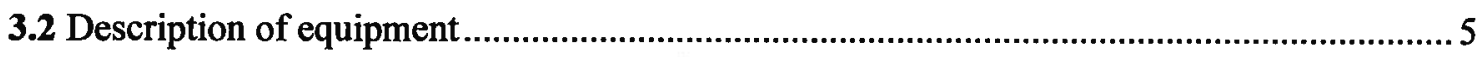

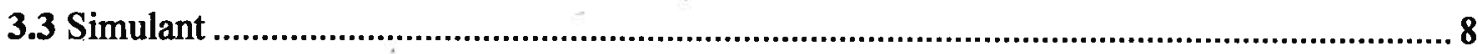

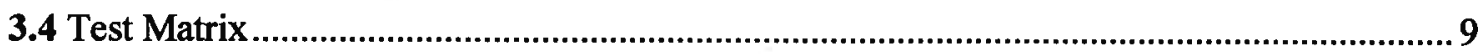

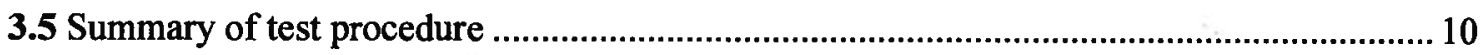

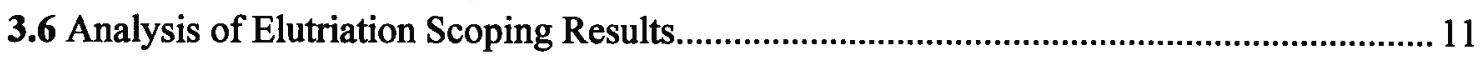

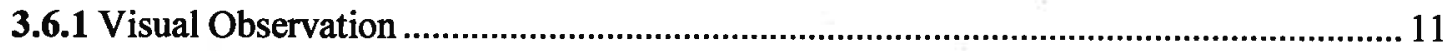

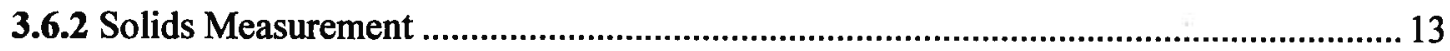

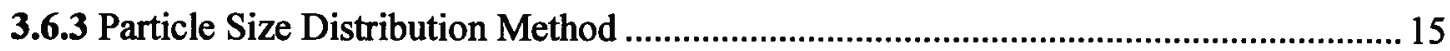

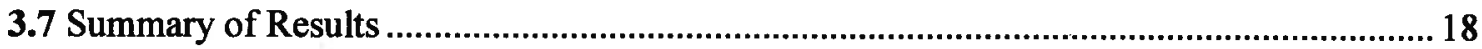

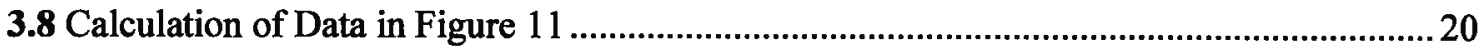

4.0 Conclusions and Recommendations for Path Forward ..................................................... 22

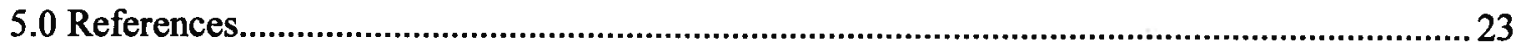




\section{LIST OF TABLES}

Table 1: $\quad$ Parameters Associated with Hanford Tank and SRNL Scaled Tank............................. 7

Table 2 Supernatant Simulant Used in Elutriation Scoping Tests......................................... 8

Table 3 Particles Used in Elutriation Scoping Tests.........................................................

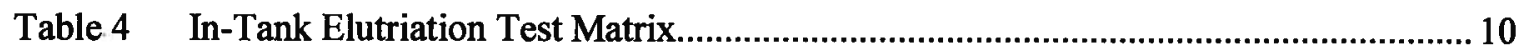

Table $5 \quad$ Volumes of Fast and Slow-Settling Solids ........................................................ 14

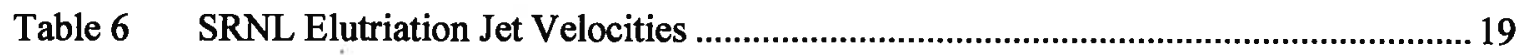

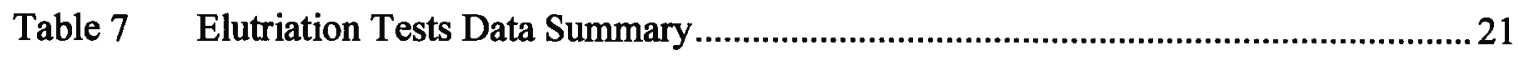

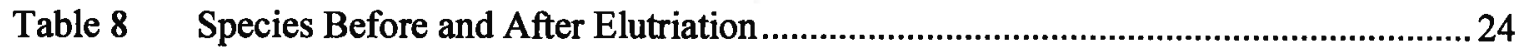

Table 9 Radionuclides Before and After Elutriation ........................................................ 25

\section{LIST OF FIGURES}

Figure 1 Generalized Drawing of 100 Series Hanford Tank ................................................. 2

Figure 2 Photograph of the Mixing/Transfer Demonstration System used for the In-Tank

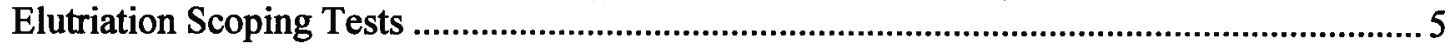

Figure 3: Schematic of the Elutriation Test System ...........................................................6

Figure 4 Photograph of Scaled Mixing Tank with Lighter Colored, Slow-Settling Particles on Dark, Fast-Settling Particles ........................................................................................... 9

Figure 5 Mound of Dark Fast-Settling Solids Left in Mixing Tank of Test 1 at Optimum

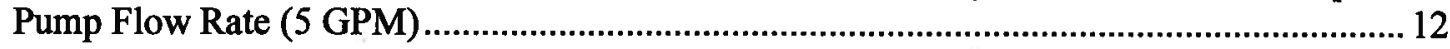

Figure 6 Light Colored Slow-Settling Solids in the Receipt Tanks of Test 1 at Optimum

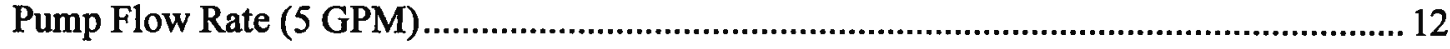

Figure 7 Dark, Fast-Settling Solids entrained and in Receipt Tank of Test 7 at High Pump

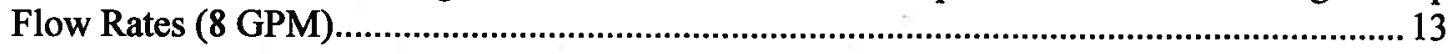

Figure 8 Bimodal Particle Size Distribution in Elütriation Simulant ..................................... 16

Figure 9 Particle Size Distributions for Tank Residue....................................................... 17

Figure 10 Particle Size Distributions for Receipt Tanks, Test 7 ......................................... 18

Figure 11 Trends - Increasing Fast-Settling Solids in Receipt Tanks with Increasing Jet Velocity 20 


\section{LIST OF ABBREVIATIONS}

$\begin{array}{ll}\text { DST } & \text { Double Shell Tank } \\ \text { DWPF } & \text { Defense Waste Processing Facility } \\ \text { EDL } & \text { Engineering Development Laboratory } \\ \text { HLW } & \text { High Level Waste } \\ \text { LAW } & \text { Low Activity Waste } \\ \text { MJP } & \text { Mixer Jet Pump } \\ \text { PNNL } & \text { Pacific Northwest National Laboratory } \\ \text { PSD } & \text { particle size distribution } \\ \text { PVC } & \text { polyvinyl chloride } \\ \text { SRNL } & \text { Savannah River National Laboratory } \\ \text { SRS } & \text { Savannah River Site } \\ \text { SST } & \text { Single Shell Tank } \\ \text { TPA } & \text { Tri Party Agreement } \\ \text { WTP } & \text { Waste Treatment Plant }\end{array}$




\subsection{Introduction}

\subsection{Background}

Hanford Site and Savannah River Site both have dozens of waste tanks that contain approximately one million gallons of radioactive waste each. Both sites are in the process of emptying tanks and then grouting them for long term disposition. In 1989 the U. S. Department of Energy (DOE), which operates the Hanford Site, the U. S. Environmental Protection Agency, and the State of Washington signed a comprehensive cleanup and compliance agreement called the Tri Party Agreement (TPA). The TPA goal for emptying tanks is to remove waste until less than 360 cubic feet of waste is left [Barton 2009]. Starting in 2003 Hanford Site inadvertently discovered a method involving elutriation that has the potential to greatly decrease the amount of radioactive contaminants left in a salt waste tank. Therefore, it may be possible to leave more non-hazardous material in the tank and reduce the cost of tank closure.

\subsection{Benefits of Elutriation}

Elutriation is a process of separating particles from one another based on size and density relationships [Kirk-Othmer]. Usually performed up-flow, it might be thought of as the inverse of differential settling. As the result of an inadvertent elutriation, retrieval of Tank S-112 waste led to a heel composed almost entirely of large $(-100 \mu \mathrm{m})$ particles of pure gibbsite, $\mathrm{Al}(\mathrm{OH})_{3}$. Concentrations of radionuclides in the heel, probably in the form of soluble compounds or micron sized particles, were greatly reduced relative to the pre-retrieved waste, e.g., the plutonium-239 concentration was a factor of 6 lower in the heel, curium 16 times lower, strontium 8 times lower and cesium was 246 times lower. These reductions occurred through a combination of dissolution, caustic digestion, and elutriation. Presumably, if the physical separation during retrieval was carried out intentionally, as with in-tank elutriation hardware, even better radionuclide removal from the gibbsite heel could have been obtained. If state and federal regulators could be convinced that this purified gibbsite heel does not represent a significant environmental hazard -- even if it exceeded $360 \mathrm{ft}^{3}$ in volume -- then the heel could be grouted in place during tank closure. Most of the aluminum compounds left in the tank would not be delivered to the Waste Treatment Plant (WTP), thus reducing the sodium hydroxide demand for aluminum dissolution in the WTP and decreasing the treatment time.

The primary benefit associated with successful implementation of In-Tank Elutriation would be a reduction in the volume of immobilized low-activity waste (LAW) glass to be disposed at Hanford, due to the reduced amount of aluminum in the feed to WTP and the reduced amount of sodium added at WTP for processing that aluminum. This would lead to lower costs and shorter treatment time.

\subsection{Analysis of Tank S-112 Elutriation -Independent Assessment}

\subsection{Description of Tank S-112 Retrieval and Inadvertent Elutriation}

This section is a summary of previous reports and presentations.

Cantrell, et al. [2008] summarized the retrieval of Hanford Tank S-112, shown in Figure 1. The tank went into service in 1952 and was declared inactive in 1976. The tank diameter and height are $75^{\prime}$ and $25^{\prime}$, respectively. Over its service life it was used to store waste from the redox process, evaporator bottoms, and recycling streams from 242-S Evaporator-Crystallizer. Waste 
retrieval from Tank S-112 occurred in two phases. Phase I, from September 2003 to May 2005 used salt cake dissolution and modified sluicing (using nozzles to spray the salt with water or salt solution) and removed all but 28,000 gal or $95 \%$ retrieval. In the second phase the Remote Water Lance (RWL) was installed to retrieve the hard heel. This was followed by two $25 \%$ caustic additions, enhanced sluicing and $50 \mathrm{wt} \%$ caustic addition. After final retrieval the residual waste volume was 2390 gal.

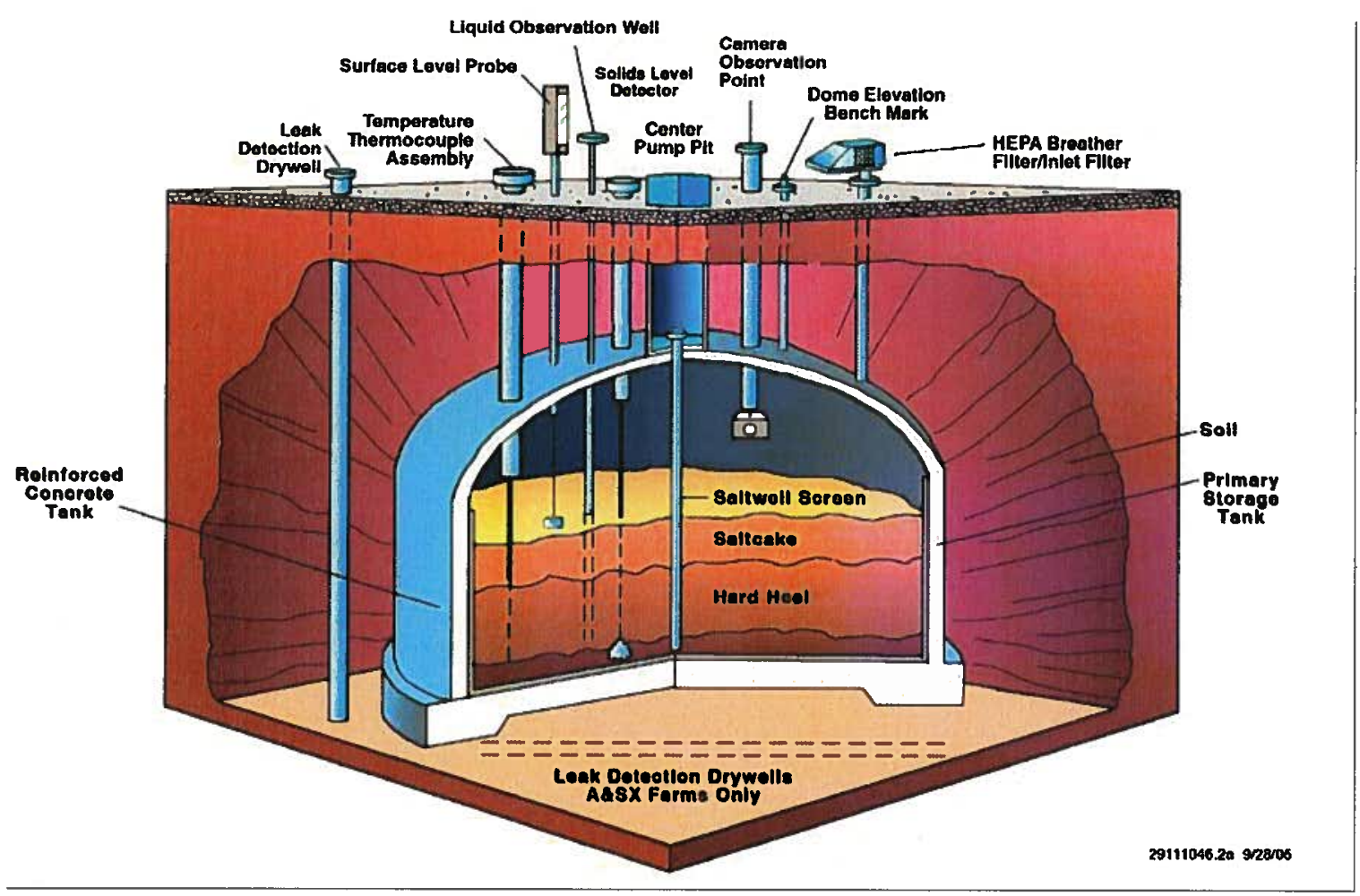

Figure 1 Generalized Drawing of 100 Series Hanford Tank

Eacker, et al [2003] described the plans for retrieving Tank S-112 and four other waste tanks at Hanford prior to retrieval. The retrieval technologies did not use previous sluicing practice which required large quantities of water. S-112 retrieval was performed with fresh water sluicing and high flow pumping systems and was expected to require two or three weeks. They planned to maintain liquid level below known tank wall leaks. S-112 retrieval was scheduled to be completed by Fall, 2003. Retrieval was to begin at the center of the tank and progress outward and use up to three directional sluicing nozzles and an automatic dual nozzle tank cleaning device. Planned pressure and flow were $550 \mathrm{kPa}$ and $375 \mathrm{~L} / \mathrm{min}$ (75 psig and $100 \mathrm{gpm})$. The transfer pump was to be a $100 \mathrm{gpm}$ progressive cavity pump or vertical turbine pump. The report included SEM images of particles as large as $300 \mu \mathrm{m}$.

Dodd [2008] reported that an estimated 53 million gallons of high-level trans-uranic and low level radioactive waste is stored underground in 149 Single Shell Tanks (SST) and 28 Double Shell Tanks (DST). The SST range in size from 55,000 gallon to $1,000,000$ gallon. TPA requires removal of as much waste as technically possible, with waste residues not to exceed $360 \mathrm{ft}^{3}$ in 530,000 gallon or larger tanks. Exceptions may be requested. Formerly they used Past Practice Hydraulic Sluicing with large volumes of DST supernatant and water. Concern over possible leaks led to the need for retrieval methods that used smaller volumes of water in a more controlled manner. As of 2008 waste retrieval had been completed at seven Hanford Site, SST 
including S-112. S-112 retrieval was completed 2/28/2007 meeting the TPA Limits of less than $360 \mathrm{ft}^{3}$ using salt cake dissolution, modified sluicing, in-tank remote controlled vehicle with high pressure water spray, and caustic dissolution. Some tanks were used in cascades such that solids separated and settled and less radioactive liquids flowed on to another tank. About $75 \%$ of the radioactivity is from $\mathrm{Sr}-90,24 \%$ is $\mathrm{Cs}-137$ and the remainder is actinides.

Barton [2009] presented a discussion of the retrieval of Tank S-112. Prior to retrieval, the tank contained 614,000 gal of mostly soluble salt. Barton expressed the opinion that the actinides in the tank, which constituted a small fraction of the total mass, were in the form of insoluble micrometer sized oxide or hydroxide particles. Starting in 2003 Hanford Site began to deinventory Salt Tank S-112 at Hanford Site as part of final disposition for the tank, which is 75' diameter and 24' tall. Hanford Site is somewhat limited in their options for performing waste removal from tanks like this because there is no steam or ventilation available and limited access to water and electricity. In preparation for tank retrieval, workers used a water lance to dig a hole in the center of the tank and lowered a $90 \mathrm{gpm}$ pump into the hole. Then they simultaneously used sluicing nozzles at the periphery of the tank. The nozzle pressure and flow were $100 \mathrm{psig}$ and $70-90 \mathrm{gpm}$. This was done for $300-500$ hours. When 25,000 gallons of salt were left, the surface was hard and relatively impermeable, like a salt lick, so they used a Salt Mantis with high pressure water to break it up. The resulting solids were light tan in color and consisted of cobble (chunks of solids the size of cobblestones) and sand. During the period from June to August 2006 they attempted to leach the residuals using 8 molar caustic solution. It was not clear that the caustic had any beneficial effect, but they were able to sluice out about one thousand additional gallons of waste from the tank.

In February 2007, Hanford workers pumped $19 \mathrm{M} \mathrm{NaOH}$ solution into the tank in anticipation that the higher viscosity and density of that liquid would facilitate solids removal. It was not necessary to purchase additional caustic because caustic was needed for corrosion control in a downstream tank. When they returned after a weekend, three days later, they saw foaming which was evidence of reaction. The cobble had disintegrated into sand. Pumpout without sluicing retrieved 1500 gal. When they were finished, the tank contained 2400 gallons, mostly gibbsite in the size range from $70 \mu \mathrm{m}$ to $200 \mu \mathrm{m}$. Gibbsite that large was surprising since it is difficult to purchase gibbsite that large. Gibbsite crystals may have grown over 30 years in the tank. The removal pump does not effectively lift particles larger than $100 \mu \mathrm{m}$. During the period June September 2007 tank solids were sampled and analyzed. Some of the solids samples were treated with different concentrations and temperatures of caustic. The dissolution tests showed no reaction at $8 \mathrm{M}$ and ambient temperature and complete reaction with $19 \mathrm{M}$ in less than two weeks. About three gallons of caustic was required per gallon of solids. Heating would greatly speed dissolution but probably is not possible for SST.

\subsection{Chemical Analysis of Tank S-112 Contents Before and After Retrieval}

The contents of Tank S-112 were sampled at different locations at least four times over a period of years before the tank contents were retrieved and again on 6/7/2007 after retrieval. The remaining solids, mostly gibbsite $\mathrm{Al}(\mathrm{OH})_{3}$, were sampled after salt removal and were analyzed for a suite of elements and anions. Aluminum and silicon were tested both by acid digestion and fusion with potassium hydroxide. Acid digestion can be incomplete when both aluminum and silicon are present. Consequently, fusion results were used to calculate average tank concentration when results from both methods were available. Also, composite core samples rather than subsegment samples were used for the "before" samples because they are more representative of tank contents. The results for chemical species and radionuclides are summarized in Table 8 and Table 9. Significant reduction in the radionuclide inventory was realized during the retrieval of Tank S-112 with the most important results summarized as follows. 
1. There were large decreases in the concentrations of nitrate and nitrite by factors of 17,000 and 1000 because those species are very soluble in water.

2. Because other species were preferentially depleted, the concentration of aluminum increased by a factor of 35 . However, most of the mass of aluminum was removed from the tank and the final mass of aluminum was one-seventh of the original mass.

3. The two biggest sources of radioactive loading (curies) were Cs-137 and $\mathrm{Sr}-90$. Their concentrations were decreased by factors of 250 and 6 and their tank inventories decreased by 60,000 and 2000 .

4. The final curie inventory was estimated to be 55. According to Appendix F in a report by the National Research Council [2006] the curie inventory in Hanford Tank C-203, for which retrieval is considered completed, was 36 . Therefore, the total curie inventory for Tank S-122 is comparable to a completed tank.

In summary, the sampling process used by Hanford in assessing the inadvertent elutriation was considered fairly representative with consideration of the uncertainties addressed below.

1. There is uncertainty in characterizing a tank using a limited number of small samples, rarely more than six. At worst the standard deviation of the samples was one-third of the average value.

2. For the purpose of computing total percent or total mass, aluminum was assumed to be in the form of gibbsite, molecular weight 78, silicon was assumed to be silicate, molecular weight 76 and sulfur was assumed to be sulfate, molecular weight 96 . Using those molecular weights, as shown in Table 1 the sums of the mass percentages of the major species for "before" and "after" were $87 \%$ and $97 \%$. Therefore, the sampling process was fairly representative.

\subsection{Evaluation of Hanford's Inadvertent Elutriation}

Elutriation of Hanford Tank S-112 would not have been as successful without the addition of large quantities of $50 \mathrm{wt} \%$ caustic. The consequences of adding large quantities of caustic to other tanks should be analyzed with the following considerations:

- Addition of caustic impacts available Double Shell Tank (DST) space and will require the evaporation of an additional 4-6L water per liter waste and the estimated cost to evaporate is $\$ 10 / \mathrm{gal}$. The minimum batch size is probably 10,000 gal of $50 \%$ caustic. Three truckloads of caustic or 12,000 gallons will react with 4200 gal of gibbsite solids.

- If high caustic is used to break up cobble, the solids should first be washed with water to remove phosphate and oxalate which would otherwise precipitate with the caustic treatment. The concept may be implemented without changes to modified sluicing retrieval systems.

In summary, based upon the Hanford experience of the inadvertent elutriation, in-tank elutriation was shown (i) to be useful in salt waste tanks and (ii) successful implementation of elutriation requires preliminary steps which have costs associated with them. The preliminary steps required for elutriation are removal of soluble salts, breaking up hard salt pan, and digesting cobble to sand using caustic solution. Since the salt waste tanks probably can not be heated, this probably means treatment with stronger than $25 \%$ caustic, although maybe not $50 \%$. Therefore, a cost and benefit analysis should be performed first. The ability to leave more innocuous gibbsite in a waste tank has benefits, but the introduction of large quantities of caustic into the waste stream has costs. The cost and benefit analysis should also consider how many tanks could use elutriation. 


\subsection{Elutriation Scoping Tests at SRNL}

\subsection{Purpose of Scoping Tests}

The purpose of the scoping tests was to demonstrate that waste tank particles can be elutriated or separated in the tank by using an existing SRNL mixing and transfer demonstration system. Specifically, parameters that influence the elutriation process were to be varied over a range. The scoping tests used the AY-102 simulant on hand with slow-settling particles (gibbsite, $30 \mu \mathrm{m}$, sp. gr. 2.42) and fast-settling particles (stainless steel, $75 \mu \mathrm{m}-100 \mu \mathrm{m}$, sp. gr. 8.03).

\subsection{Description of equipment}

A photograph and schematic of the elutriation tests system are shown in Figure 2 and Figure 3. This test system was used earlier for batch transfer demonstrations (Adamson 2009). The mixing tank wall and bottom are transparent to allow visual observations. The mixing tank (40.5" diameter, $30^{\text {" }}$ height) is a $1 / 22^{\text {nd }}$ scale replica of Hanford Tank AY-102. Table 1 provides pertinent design and operating parameters for the full size AY-102 waste tank and the $1 / 22^{\text {nd }}$ scale test tank.

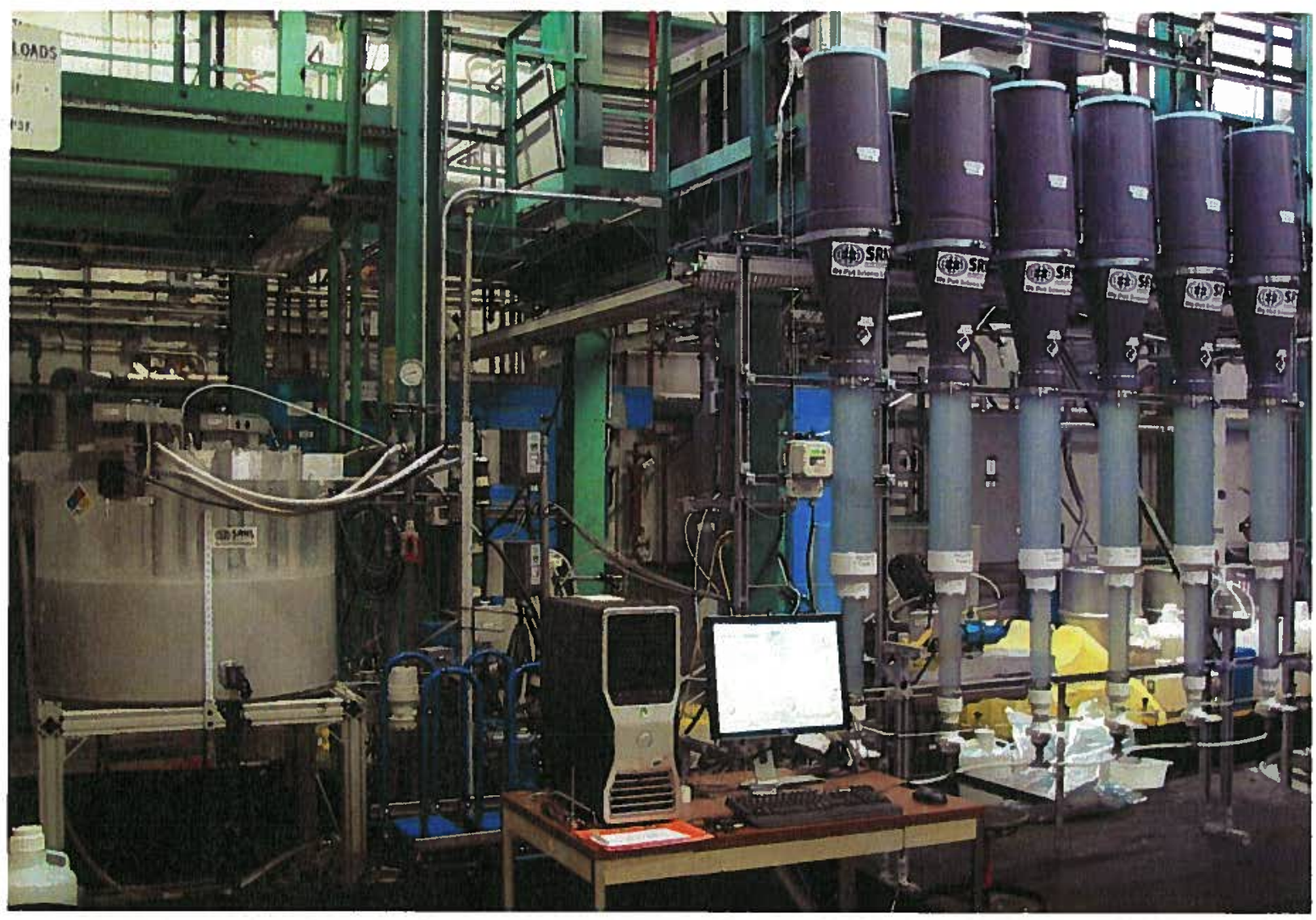

Figure 2 Photograph of the Mixing/Transfer Demonstration System used for the InTank Elutriation Scoping Tests 


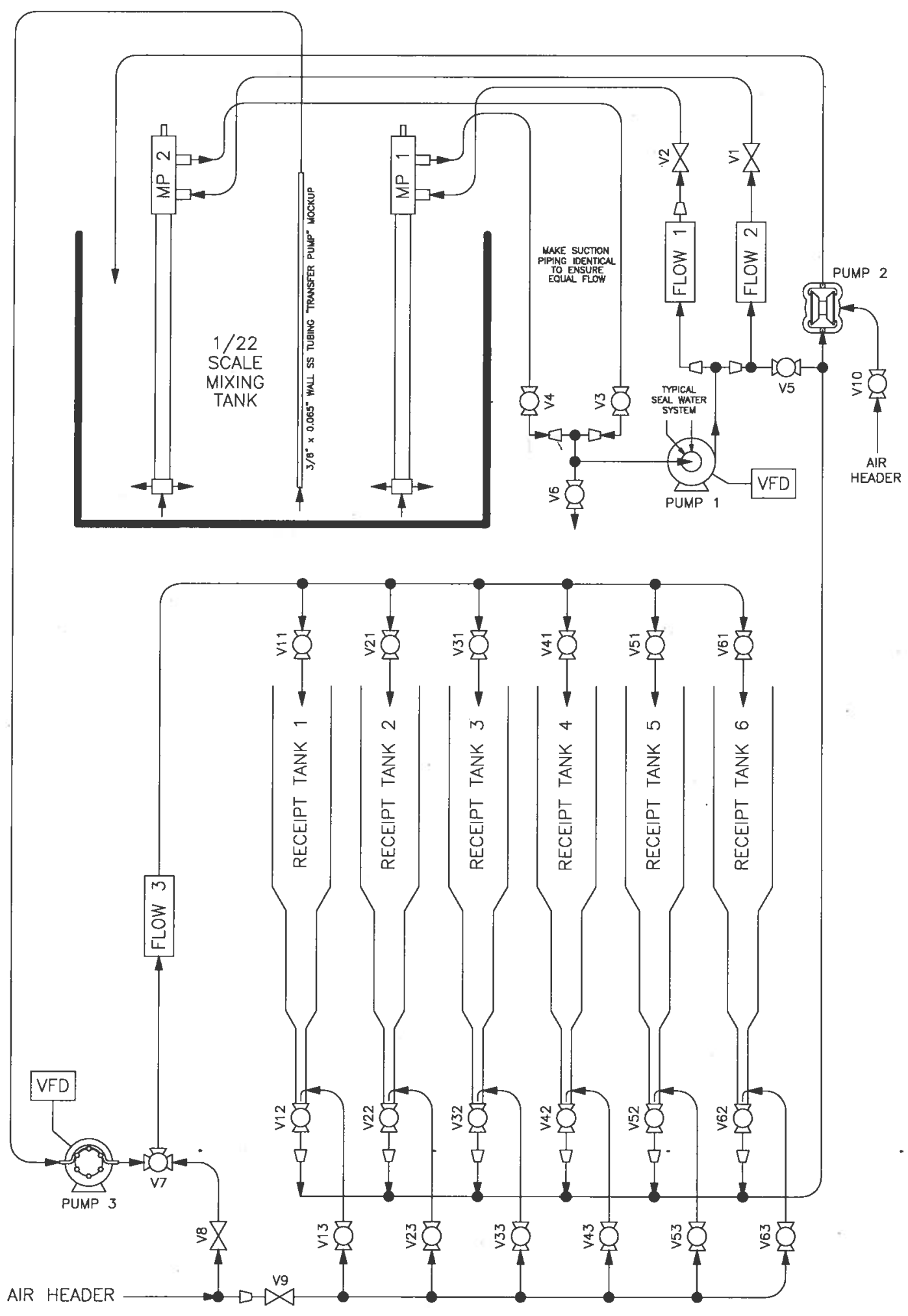

Figure 3: $\quad$ Schematic of the Elutriation Test System 
Table 1: $\quad$ Parameters Associated with Hanford Tank and SRNL Scaled Tank

\begin{tabular}{|c|c|c|}
\hline Parameter Description & Full Scale Hanford & SRNL@ $1 / 22=0.045$ scale factor \\
\hline Tank diameter & $75 \mathrm{ft}$ (900 inches) & 40.5 inches (actual 40.9") \\
\hline Tank operating height & 364 inches & 16.5 inches \\
\hline Total waste height & 347 inches & 15.6 inches \\
\hline Sludge height & 55 inches & 2.49 inches (actual 1.75") \\
\hline Supernatant height & 292 inches & 13.2 inches \\
\hline Total waste volume & $955,085 \mathrm{gal}$ & 87 gallons \\
\hline Batch volume to WTP & $160,000 \mathrm{gal}$ & $14.3 \mathrm{gal}$ \\
\hline Residence mixing time AY-102 & 45.2 minutes & \\
\hline $\begin{array}{l}\text { Flow for scaled model to have full } \\
\text { scale residence time }\end{array}$ & - & $0.47 \mathrm{gal} / \mathrm{min} / \mathrm{nozzle}$ \\
\hline $\begin{array}{l}\text { Nozzle velocity } \\
\text { residence }\end{array}$ & - & $2.6 \mathrm{ft} / \mathrm{sec}$ \\
\hline Pump location from tank center & $22 \mathrm{ft}$ & 11.9 inches \\
\hline Pump above tank bottom & 6 inches & 0.27 inches \\
\hline Nozzle diameter & 6 inches & 0.27 inches \\
\hline $\begin{array}{l}\text { Nozzle location from bottom of } \\
\text { pump }\end{array}$ & 9 inches & 0.41 inches \\
\hline Pump rotational speed & $0.2 \mathrm{rpm}$ & $1.6 \mathrm{rpm}$ \\
\hline $\begin{array}{l}\text { Pump flowrate } \\
\text { Nozzle Exit Velocity }\end{array}$ & $\begin{array}{l}5280 \mathrm{gal} / \mathrm{min} / \mathrm{nozzle} \\
60 \mathrm{ft} / \mathrm{sec}\end{array}$ & $\begin{array}{l}10.8 \mathrm{gal} / \mathrm{min} / \text { nozzle } \\
60 \mathrm{ft} / \mathrm{sec}\end{array}$ \\
\hline $\mathrm{U}_{0} \mathrm{D}$ & $30 \mathrm{ft}^{2} / \mathrm{s}$ & $1.35 \mathrm{ft}^{2} / \mathrm{s}$ \\
\hline $\mathrm{U}_{0} \mathrm{D}$ at a flowrate of $8 \mathrm{gpm}$ MJP & & $0.504 \mathrm{ft}^{2} / \mathrm{s}$ \\
\hline $\mathrm{U}_{0} \mathrm{D}$ at a flowrate of $5 \mathrm{gpm} \mathrm{MJP}$ & & $0.315 \mathrm{ft}^{2} / \mathrm{s}$ \\
\hline $\begin{array}{l}1 / 22^{\text {nd }} \text { Pump flowrate (8 gpm) } \\
\text { Nozzle Exit Velocity }\end{array}$ & - & $\begin{array}{l}4 \mathrm{gal} / \mathrm{min} / \text { nozzle } \\
22.4 \mathrm{ft} / \mathrm{sec} / \text { nozzle }\end{array}$ \\
\hline $\begin{array}{l}\left.1 / 22^{\text {nd }} \text { Pump flowrate ( } 5 \mathrm{gpm}\right) \\
\text { Nozzle Exit Velocity }\end{array}$ & $\begin{array}{ll}- \\
-\end{array}$ & $\begin{array}{l}2.5 \mathrm{gal} / \mathrm{min} / \text { nozzle } \\
14 \mathrm{ft} / \mathrm{sec} / \text { nozzle }\end{array}$ \\
\hline Pump flowrate (power cal.) & $5280 \mathrm{gal} / \mathrm{min} / \mathrm{nozzle}$ & $5.0 \mathrm{gal} / \mathrm{min} / \mathrm{nozzle}$ \\
\hline Nozzle velocity (power calculation) & $60 \mathrm{ft} / \mathrm{sec}$ & $28 \mathrm{ft} / \mathrm{sec}$ \\
\hline $\mathrm{U}_{0} \mathrm{D}$ (power calculation) & - & $0.63 \mathrm{ft}^{2} / \mathrm{s}$ \\
\hline Liquid density & $1,150 \mathrm{~kg} / \mathrm{m}^{3}$ & $1,289 \mathrm{~kg} / \mathrm{m}^{3}$ \\
\hline Solids density & $2,500 \mathrm{~kg} / \mathrm{m}^{3}$ & $\begin{array}{l}\text { Gibbsite: } 2,420 \mathrm{~kg} / \mathrm{m}^{3} \\
\text { Stainless steel: } 8,000 \mathrm{~kg} / \mathrm{m}^{3}\end{array}$ \\
\hline Viscosity of liquid & $2.8 \mathrm{cP}$ & $2.55 \mathrm{cP}$ \\
\hline Air Lift Circ. (ALC) dia. (22 in tank) & 30 inches & $1.35 "$ (used 1.25") \\
\hline ALC elevation above tank bottom & 30 inches & 1.35 inches \\
\hline Heating coil dia. ( 1 in tank) & 40.375 inches & $1.8 "$ (used 1.75") \\
\hline Transfer pump outer diameter & 12 inches & 0.54 " (used 3/8" sst tube) \\
\hline Transfer pump inlet diameter & 2.25 inches & $0.1 "$ (used $0.125 ")$ \\
\hline Transfer pump above tank bottom & 5 inches & 0.23 inches \\
\hline Transfer pump, pump rate & $90-140 \mathrm{gpm}$ & $0.58 \mathrm{gpm}$ \\
\hline Transfer pump, velocity & $3.9 \mathrm{ft} / \mathrm{s}, 6.1 \mathrm{ft} / \mathrm{s}$ & $3.95 \mathrm{ft} / \mathrm{s}$ in $3 / 8 ", 0.025 \mathrm{ft} / \mathrm{s}$ in $3^{\prime \prime}$ \\
\hline Batch transfer volume & 160,000 gal & $14.3 \mathrm{gal}$ \\
\hline Particle size distribution & $2.5 \sim 16.8 \mu \mathrm{m}$ & $\begin{array}{l}\text { stainless steel - } 75 \text { to } 106 \mu \mathrm{m} \\
\text { gibbsite } 30 \mu \mathrm{m}\end{array}$ \\
\hline
\end{tabular}


The test tank was provided with internal obstructions to achieve prototypic geometry. The tank has prototypical obstructions, a transfer pump feed line and two Mixer Jet Pumps (MJPs). The slurry pump that fed the mixer jets was located outside the test tank and its speed was controlled by a variable speed drive. Fluid was pumped from the test tank and then circulated back to the $1 / 22^{\text {nd }}$ scale MJPs. Each MJP has two nozzles oriented $180^{\circ}$ apart.

The six Receipt Tanks shown in Figures 2 and 3 are transparent PVC over most of their length to allow for measurement of the volume of solids that were transferred in each test. The Receipt Tanks hold approximately 22 gallons each.

Testing was conducted per the R\&D Direction summarized in Section 3.4. Test results were also recorded in Laboratory Notebook, SRNL-NB-2010-00124.

\subsection{Simulant}

The supernatant used in all of the scoping in-tank elutriation testing was prepared for a previous task at SRNL. The supernatant was intended to represent waste in an average Hanford waste tank. The supernatant itself is transparent. The recipe for this simulant is given in the "Revised Preparation of Simulated Feed Solution for Pilot Plant", CH2M-0701541.1 report (July, 2007). The recipe was modified from the report recipe by the removal of the sodium dichromate to prevent the simulant from being classified as a hazardous solution. The composition of the supernatant is shown in Table 2.

Table 2 Supernatant Simulant Used in Elutriation Scoping Tests

\begin{tabular}{|l|c|}
\hline \multicolumn{1}{|c|}{ Chemical } & g/liter \\
\hline $\mathrm{NaAlO}_{2}{ }^{*} \mathrm{H}_{2} \mathrm{O}$ & 29.18 \\
\hline $\mathrm{NaOH}$ & 24.49 \\
\hline $\mathrm{Na}_{2} \mathrm{CO}_{4}$ & 65.71 \\
\hline $\mathrm{Na}_{2} \mathrm{C}_{2} \mathrm{O}_{4}$ & 0.81 \\
\hline $\mathrm{KNO}_{3}$ & 1.80 \\
\hline $\mathrm{NaNO}_{3}$ & 279.63 \\
\hline $\mathrm{NaNO}_{2}$ & 35.88 \\
\hline $\mathrm{NaSO}_{4}$ & 18.41 \\
\hline $\mathrm{Na}_{3} \mathrm{PO}_{4}{ }^{*} 12 \mathrm{H}_{2} \mathrm{O}^{*} 1 / 4 \mathrm{NaOH}$ & 18.09 \\
\hline $\mathrm{NaCl}$ & 4.30 \\
\hline $\mathrm{NaF}$ & 0.42 \\
\hline & \\
\hline
\end{tabular}

The supernatant was spiked with particles that represented both fast-settling and slow-settling particles in tank waste. The critical parameter in elutriation is the settling velocity which considers both the particle size and the density of the particle. Since large-size gibbsite particles representative of those in the Hanford S-112 tank (i.e., greater than $200 \mu \mathrm{m}$ ) are not commercially available, $100 \mu \mathrm{m}$ stainless steel was utilized in its place since the settling velocities were comparable. Small size gibbsite particles at $30 \mu \mathrm{m}$ represented the slow-settling particles that would represent radionuclides in the tanks. The solid particles used for these tests are characterized in Table 3. The fast-settling particles were dark and the slow-settling particles were light to allow visual evaluation on the performance of the separation. Figure 4 is a photograph of the simulant in the mixing tank prior to mixing. The light color slow-settling particles are seen 
resting above the thin dark color fast-settling particles. This color intensity distinction was used in the analysis of the test results.

Table 3 Particles Used in Elutriation Scoping Tests

\begin{tabular}{|l|l|l|l|l|l|}
\hline Particle & Composition & Size $(\mu \mathrm{m})$ & $\begin{array}{l}\text { Density } \\
(\mathrm{kg} / \mathrm{m} 3)\end{array}$ & Color & $\begin{array}{l}\text { Mass in } \\
\text { simulant, lb. }\end{array}$ \\
\hline Fast-settling & Stainless steel & $\sim 100$ & $\mathbf{8 , 0 0 0}$ & dark & 23.2 \\
\hline Slow-settling & gibbsite & $\sim 30$ & 2,420 & light & $\mathbf{8 2 . 6}$ \\
\hline
\end{tabular}

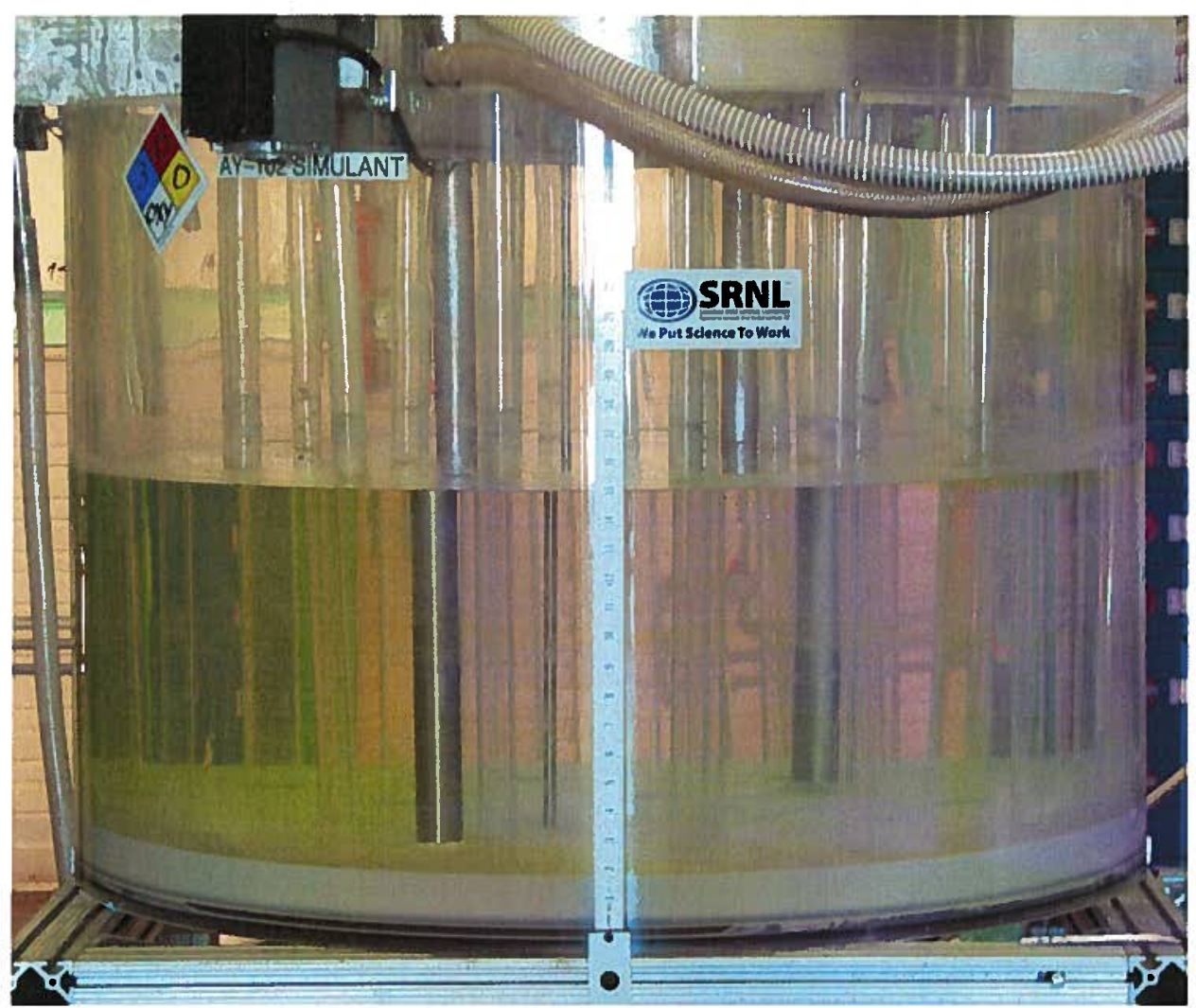

Figure 4 Photograph of Scaled Mixing Tank with Lighter Colored, Slow-Settling Particles on Dark, Fast-Settling Particles

\subsection{Test Matrix}

A total of seven elutriation tests were performed as shown in Table 4. The following three parameters were identified that may have an impact on the Phase 1 elutriation tests:

- mixing pump flowrate

- suction tube diameter

- $\quad$ suction tube elevation above tank bottom

As shown in Table 4, the flow rate for each mixing pump was varied over a range of $4-8 \mathrm{gpm}$, because 4 and $8 \mathrm{gpm}$ were considered to be bounding cases. For the slurry transfer out of the mixing tank two suction tube sizes were tested. The first five tests used a 3/8" OD, 0.065 " wall stainless steel tube providing a velocity of about $4 \mathrm{ft} / \mathrm{s}$ at the suction point. The last two tests were performed with a 3 " SCH 40 pipe section at the suction point resulting in a suction velocity of 
$0.025 \mathrm{ft} / \mathrm{s}$. An additional variable was the suction tube elevation above the tank bottom. Four tests were performed at a tube elevation of 0.25 " and three at 1.25 ". Both mixing pumps rotated at a constant speed of $1.6 \mathrm{rpm}$ for all seven tests. The orientations of the nozzles of the two mixing pumps were not synchronized to yield a randomized mixing operation.

Table 4 In-Tank Elutriation Test Matrix

\begin{tabular}{|c|c|c|c|c|c|}
\hline $\begin{array}{c}\text { Test } \\
\text { No. }\end{array}$ & Test Date & $\begin{array}{c}\text { Flow Rate } \\
\text { per } \\
\text { Mixing } \\
\text { Pump*, } \\
\text { gpm }\end{array}$ & $\begin{array}{c}\text { Suction } \\
\text { Tube OD, } \\
\text { inch }\end{array}$ & $\begin{array}{c}\text { Suction } \\
\text { Tube ID, } \\
\text { inch }\end{array}$ & $\begin{array}{c}\text { Suction } \\
\text { Tube } \\
\text { Elevation } \\
\text { above Tank } \\
\text { Bottom, inch }\end{array}$ \\
\hline 1 & $9 / 1 / 2010$ & 5 & 0.375 & 0.245 & 0.25 \\
\hline 2 & $9 / 13 / 2010$ & 4 & 0.375 & 0.245 & 0.25 \\
\hline 3 & $9 / 16 / 2010$ & 6 & 0.375 & 0.245 & 0.25 \\
\hline 4 & $9 / 22 / 2010$ & 5 & 0.375 & 0.245 & 1.25 \\
\hline 5 & $9 / 27 / 2010$ & 4 & 0.375 & 0.245 & 1.25 \\
\hline 6 & $10 / 1 / 2010$ & 5 & 3.5 & 3.068 & 0.25 \\
\hline 7 & $10 / 4 / 2010$ & 8 & 3.5 & 3.068 & 1.25 \\
\hline
\end{tabular}

* Each mixing pump has two nozzles

\subsection{Summary of test procedure}

As discussed above, a total of seven elutriation tests were performed by following detailed set of step by step instructions, which are summarized below.

1. Load the Mixing Tank with Fractional Crystallization simulant, which was also a AY-102 simulant, as described in section 3.2 (about 87 gallons, $82.6 \mathrm{lbs}$ of gibbsite ( $<30$ micron) and $23.2 \mathrm{lbs}$ of stainless steel particles (nominally, 100 micron). Note: the simulant was mixed in 2008 so some of the sodium hydroxide reacted to form additional sodium carbonate.

2 . Set the suction tube elevation as shown in the test matrix, Table 2 above.

3. Rotate the MJPs at $1.6 \mathrm{rpm}$.

5. Provide both MJPs with $10 \mathrm{gpm}$ flow each to mix the tank contents for 10 minutes.

6. Pull samples from the mixed tank for particle size distribution (PSD)-analysis.

7. Reduce the MJP flow rate according to the test matrix.

8. Observe and record photographically any formation of no mixing zones ("dead zones").

9. Start transfer of first batch (about one-sixth of total inventory) out of the mixing Tank at 0.58 gpm using Pump 3.

10. At the completion of the first batch, continue transferring the subsequent five batches. Note that Pump 3 is not turned off in between different batches.

11. At the conclusion of all six transfers, stop the flow and rotation of the MJPs.

12. Collect a representative sample of the mixing tank heel contents for PSD analysis. 
13. Record the levels in the Receipt Tanks for total amount of slurry and solids levels after solids have settled.

14. Mix the contents of Receipt Tanks using air sparging and collect representative samples for PSD analyses from Receipt Tanks 1, 3 and 5.

15. Transfer contents of all Receipt Tanks back to the mixing tank to prepare for the next test per the test matrix. Use air sparging as needed to empty out the Receipt Tanks.

\subsection{Analysis of Elutriation Scoping Results}

The elutriation results from varying the tank parameters: (i) mixing jet pump flowrate, (ii) suction tube diameter, and (iii) suction tube elevation are discussed in this section. The elutriation results were quantified using three methods:

1) Visual Observation - The first method of quantification was visual observation, which included both observations of solids remaining in the mixing tank and in the receipt tanks. The simulant was spiked with both fast-settling particles (dark color) and slowsettling particles (light color) to allow a quick visual determination of separation effectiveness. The impact of the test parameters can be immediately assessed visually and corresponded to the physical measurements used in methods 2) and 3) discussed below.

2) Solids Measurement (Volume) - The second method included measurement of the solids heights in the six Receipt Tanks after each of the tests and computation of the approximate volumes of the fast-settling and slow-settling solids. The tanks had been previously calibrated to give volume as a function of solids height [Adamson, et al. 2010].

3) Particle Size Distribution Measurement - The third method involved analytical measurement of the samples removed from the mixing tank.

\subsubsection{Visual Observation}

The most significant parameter tested that impacted separations was the mixing jet pump (MJP) flowrate. Figures 5 through 7 illustrate the effectiveness of the MJP flowrate in achieving separation between the particles remaining in the tank and those that are removed to the six (6) receipt tanks. In Figure 5, the separation effectiveness of using a MJP velocity of $5 \mathrm{gpm}$ (Test 1 ) is shown in that most of the darker fast-settling solids remain in the mixing tank with very little light-colored slow-settling solids. In Figure 6, the opposite effect is shown in that most of the light-colored slow-settling solids were removed to the Receipt Tanks with very little dark-colored solids. In Figure 7, both dark and light colored solids are shown in the Receipt Tank which would be expected when the MJP flowrate was increased to $8 \mathrm{gpm}$ (Test 7) to the point that even the fast-settling solids are entrained with the slow-settling solids and removed to the Receipt Tanks. Several samples were taken from both the Receipt Tank and the mixing tank to obtain particle size distribution of the solids. 


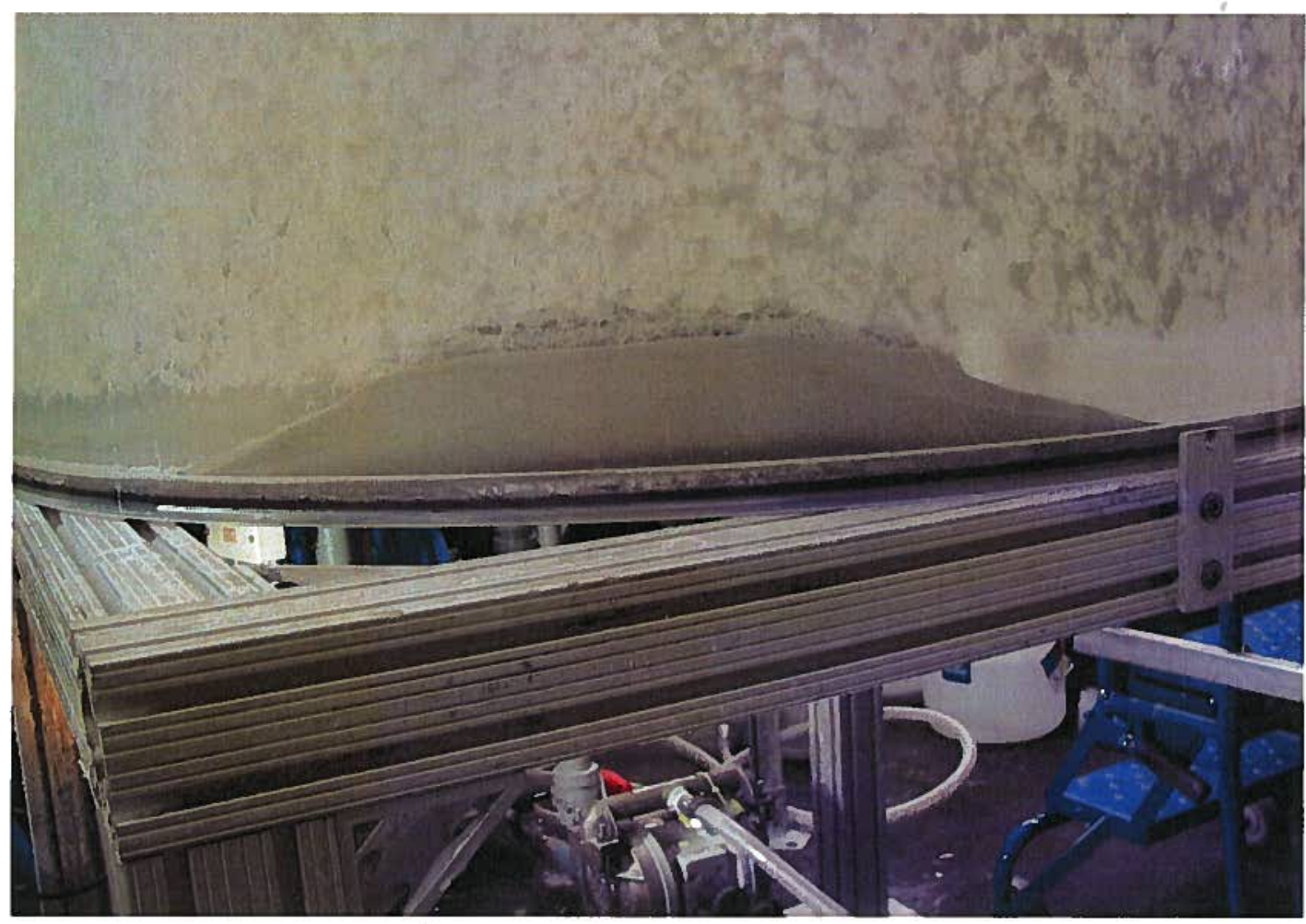

Figure 5 Mound of Dark Fast-Settling Solids Left in Mixing Tank of Test 1 at Optimum Pump Flow Rate (5 GPM)

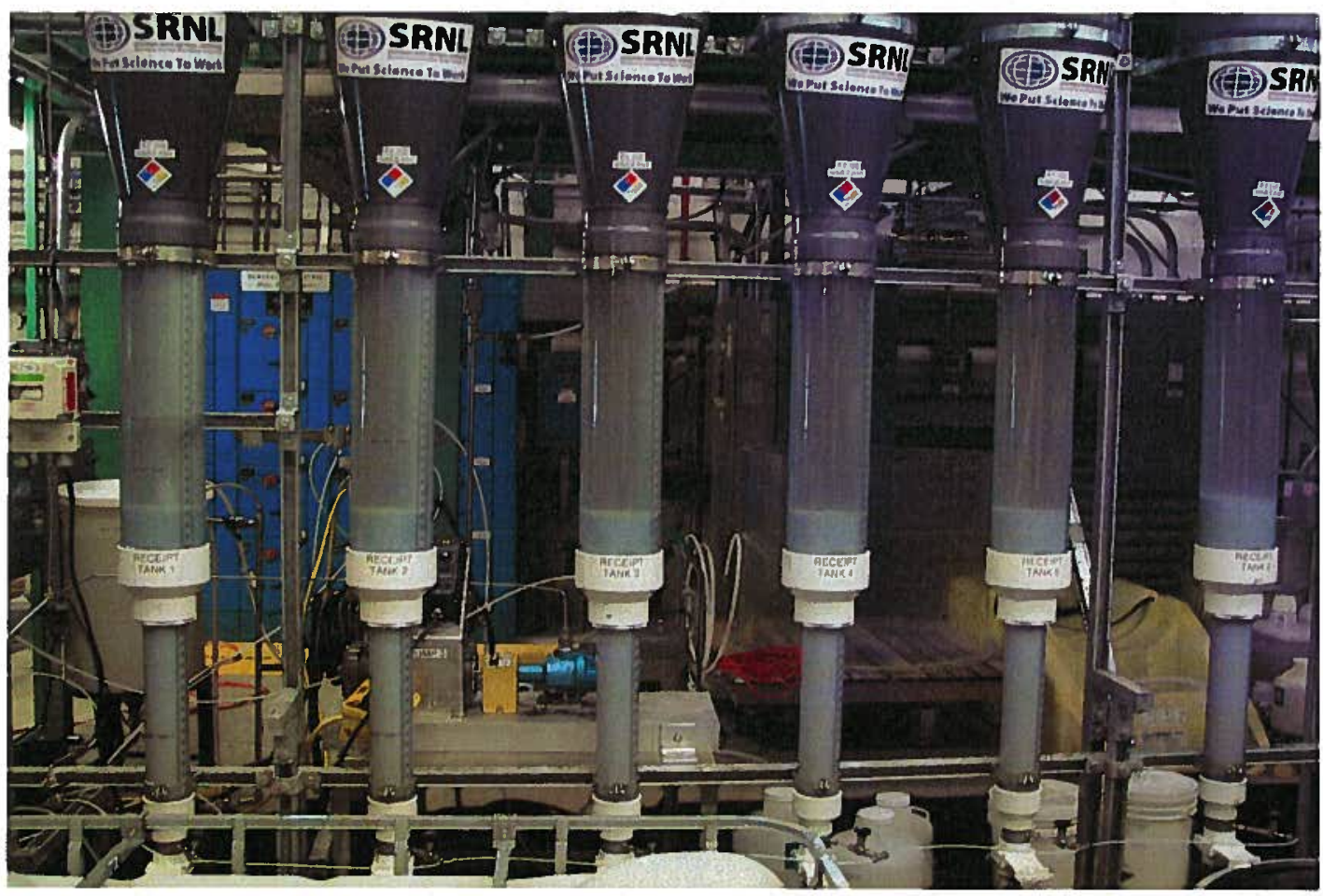

Figure 6

Light Colored Slow-Settling Solids in the Receipt Tanks of Test 1 at Optimum Pump Flow Rate (5 GPM) 


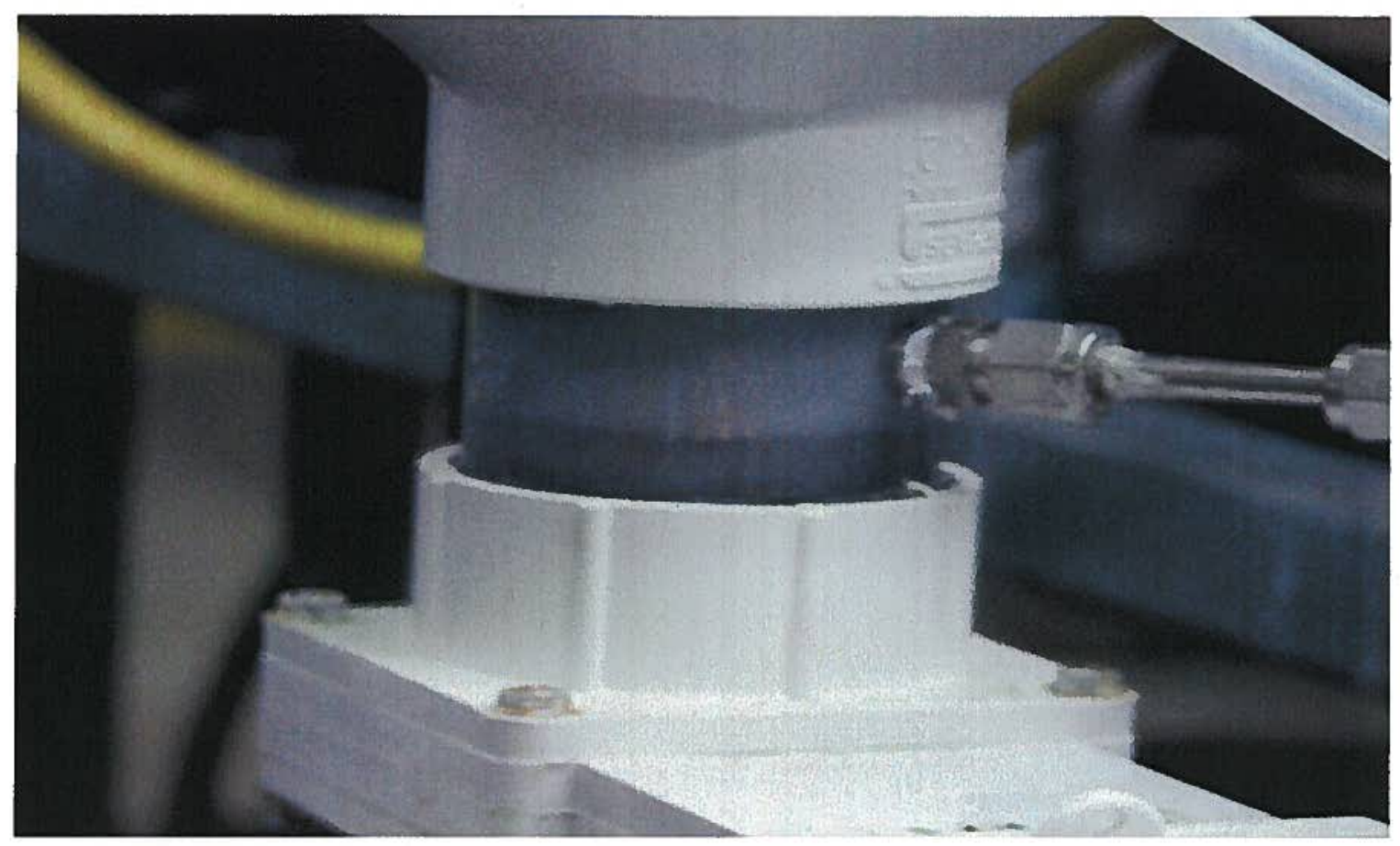

Figure 7 Dark, Fast-Settling Solids entrained and in Receipt Tank of Test 7 at High Pump Flow Rates (8 GPM)

\subsubsection{Solids Measurement}

For optimum separation efficiency, the goal is to operate the MJP flow rate and other tank parameters such that minimal fast-settling solids are entrained into the Receipt Tanks (RTs). Table 5 gives volumes of fast and slow-settling solids for the six Receipt Tanks (RT1-6) resulting from the seven test runs shown in Table 3. The following are observations and comments about the data shown in Table 5.

1. As expected, testing showed that less than optimum separation efficiency resulted at higher pump flow rates due to the entrainment of fast-settling solids with the slowsettling solids.

a. For example, tests run at the higher pump flow rates of 6 to $8 \mathrm{gpm}$ (Tests 3 and 7) resulted in the most fast-settling solids in the RTs as shown in Table 5.

b. For tests run at 4 and 5 gpm (Tests 1,2 and 5), Table 5 shows there was little or no fast-settling solids in the RTs.

2. The test results showed there is an optimum MJP flow rate that results in optimum separation. In this testing, tests run at MJP flow rates of $5 \mathrm{gpm}$ resulted in optimum separation where the heavier fast-settling solids remained in the MDT and the lighter slow-settling solids were removed to the RTs. Test runs at higher MJP flow rates resulted in heavier solids that were entrained at the higher flow rates interfering in the removal of the lighter solids that normally would have been separated and removed to the RTs.

c. For test runs at the higher flow rates of 6 and $8 \mathrm{gpm}$ (Tests 3 and 7) and at the higher suction tube elevation (Test 4), the RTs contained less than the average volume of slow-settling solids indicating that some slow-settling remained behind in the MDT. 
SRNL-STI-2011-00227

Revision 0

Table $5 \quad$ Volumes of Fast and Slow-Settling Solids

\begin{tabular}{|c|c|c|c|c|c|c|c|}
\hline Test \# & RT-1 & RT-2 & RT-3 & RT-4 & RT-5 & RT-6 & $\begin{array}{l}\text { Total } \\
\text { (gal) }\end{array}$ \\
\hline \multicolumn{8}{|c|}{ Fast-Settling Solids } \\
\hline 1 & 0.00 & 0.00 & 0.00 & 0.00 & 0.00 & 0.00 & 0.00 \\
\hline 2 & 0.00 & 0.00 & 0.00 & 0.00 & 0.00 & 0.00 & 0.00 \\
\hline 3 & 0.25 & 0.24 & 0.23 & 0.23 & 0.23 & NR* & 1.17 \\
\hline 4 & 0.04 & 0.04 & 0.04 & 0.04 & 0.04 & 0.04 & 0.22 \\
\hline 5 & 0.00 & 0.00 & 0.00 & 0.00 & 0.00 & 0.00 & 0.00 \\
\hline 6 & 0.04 & 0.04 & 0.04 & 0.04 & 0.04 & 0.04 & 0.22 \\
\hline 7 & 0.14 & 0.10 & 0.11 & 0.10 & 0.11 & 0.00 & 0.56 \\
\hline Total & & & & & & & 2.17 \\
\hline \multicolumn{8}{|c|}{ Slow-Settling Solids } \\
\hline 1 & 1.76 & 1.67 & 1.63 & 1.65 & 1.69 & 1.74 & 10.13 \\
\hline 2 & 2.26 & 2.14 & 2.10 & 1.98 & 2.06 & NR & 10.54 \\
\hline 3 & 1.70 & 1.72 & 1.67 & 1.61 & 1.70 & NR & 8.41 \\
\hline 4 & 1.83 & 1.76 & 1.75 & 1.74 & 1.75 & 0.92 & 9.76 \\
\hline 5 & 2.08 & 2.04 & 1.99 & 1.96 & 1.91 & 0.96 & 10.95 \\
\hline 6 & 2.51 & 2.67 & 2.73 & 2.78 & 2.63 & 2.27 & 15.59 \\
\hline 7 & 1.57 & 1.56 & 1.54 & 1.55 & 1.57 & 0.51 & 8.30 \\
\hline Total & & & & & & & \\
\hline
\end{tabular}

* Not measured

b. For test runs at 4 and $5 \mathrm{gpm}$ (Tests 1,2 and 5), nearly all of the slow-settling was transferred to the Receipt Tanks. Also for Tests 1, 2 and 5 little or no fastsettling particles transferred to the Receipt Tanks.

c. For test runs at higher MJP flow rates and at higher suction tube elevations (Test $3,4,6$ and 7, significant amount of fast-settling particles were transferred. For Test 3, all or nearly all of the fast-settling particles transferred.

3. The testing demonstrated excellent tank mixing and consistency in the batch transfers to each of the RTs. This consistency was demonstrated by the test results that showed an even distribution of the fast-settling solids between the six RTs. Also, for a given test, the volumes of the light- colored slow-settling solids in the six Receipt Tanks were approximately equal.

4. There were sources of uncertainty in the data:

a. In the previous section of this report it was noted that 82.6 pounds of gibbsite (slow-settling solids) was initially added to the mixing tank. The "loose pack" bulk density of gibbsite was measured and was approximately $0.86 \mathrm{~g} / \mathrm{mL}$. Note, that this density is much less than the published density of non-porous gibbsite, $2.42 \mathrm{~g} / \mathrm{mL}$. The mass of gibbsite translates to a volume of $11.5 \mathrm{gal}$. The total volumes of gibbsite in Table 5 ranged from $8.3 \mathrm{gal}$ to $15.59 \mathrm{gal}$. It is not known why for Test 6 there appeared to be more total gibbsite volume in the Receipt Tanks than was originally in the mixing tank. 
b. In the previous section of this report it was noted that 23.2 pounds of stainless steel powder were initially added to the mixing tank. The "loose pack" bulk density of stainless steel powder was measured and was approximately 2.55 $\mathrm{g} / \mathrm{mL}$. Note, that this density is much less than the published density of stainless steel, $8.03 \mathrm{~g} / \mathrm{mL}$. The mass of stainless steel translates to a volume of $1.09 \mathrm{gal}$.

c. Figure 6 shows that some of the plastic fittings in the Receipt Tanks are opaque. Therefore, there is large uncertainty associated with some of the stainless steel volumes. For example, the readings of zero volume may actually be 0.01 gallon. Also, the uncertainty for stainless steel volumes for Test 7 is $\pm 35 \%$.

d. Gibbsite heights for RT-6 are uncertain because the readings were obscured by an opaque 6" reducer.

\subsubsection{Particle Size Distribution Method}

The final method for quantifying separation performance was by use of Particle Size Distributions (PSDs). Figure 8 shows the PSD of a sample from the mixing tank that contains both fast-settling and slow-settling particles prior to testing and compares it to the PSDs of vendor samples for both fast- and slow-settling particles. The fast-settling, stainless steel particles had been sieved by the manufacturer to be $106 \mu \mathrm{m}$ or less, however the PSD volume peaks were at $134 \mu \mathrm{m}$ as shown in Figure 8. The vendor's method of cold-working the stainless steel altered the crystal structure to make the particles magnetic and allowed some of the particles to form clumps as large as $300 \mu \mathrm{m}$. However, in the RTs, the sizes were at a maximum of 100 microns because the clumps were sheared apart inside the transfer and mixing pumps. Figure 8 shows the bi-modal size distribution in the simulant which is anticipated with the addition of both the larger fast-settling stainless steel particles and the smaller slow-settling particles (approximate peak at $23 \mu \mathrm{m}$ ). 


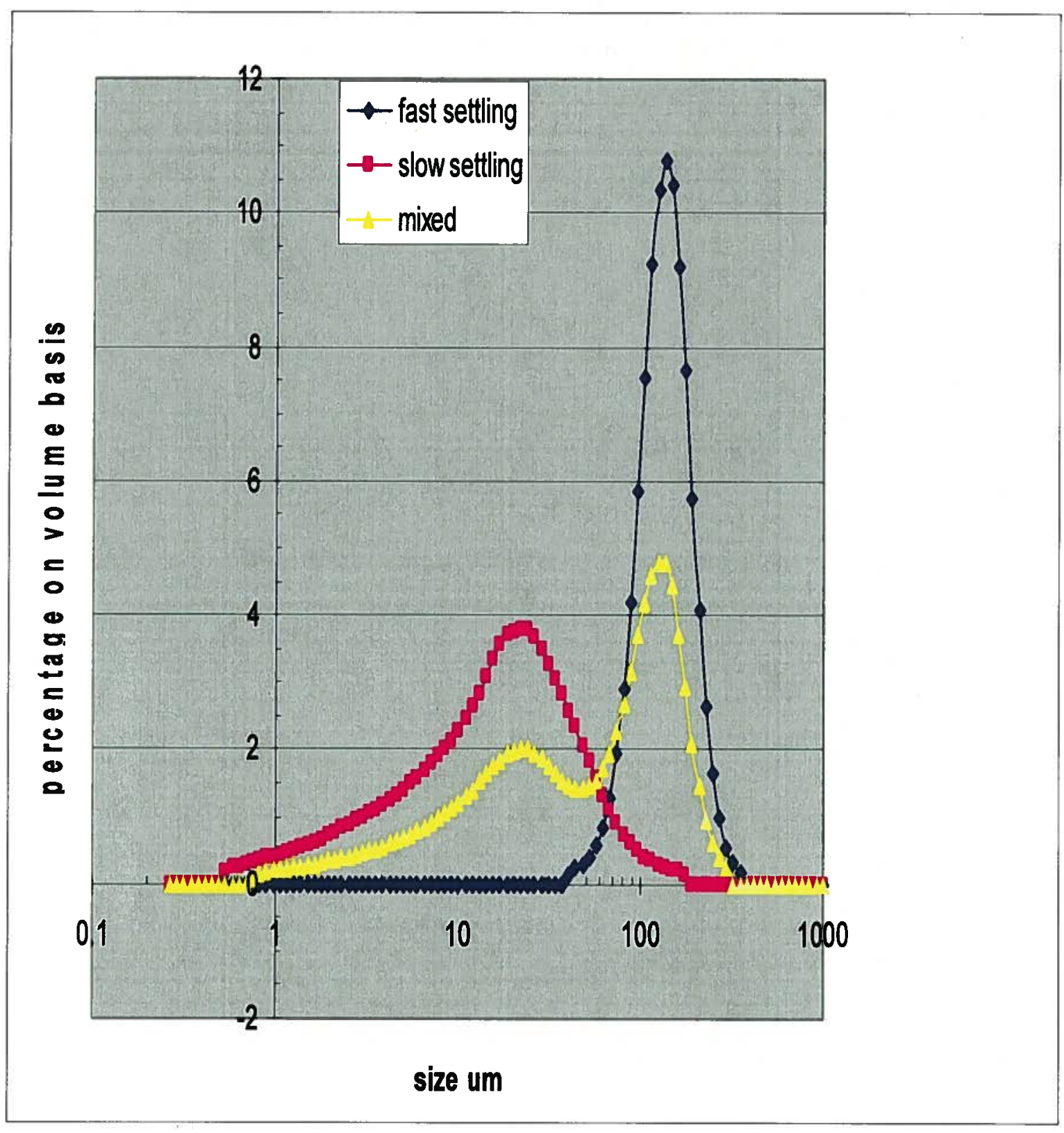

Figure 8 Bimodal Particle Size Distribution in Elutriation Simulant

Figure 9 shows the PSDs for the residual solids in the tank after the completion of elutriation as well as the PSD for the as-received (vendor) fast settling particles. For the as-received fastsettling particles there were no particles with sizes less than or equal to $37 \mu \mathrm{m}$. However, in some of the tests, particularly tests conducted at slower MJP velocities of $4 \mathrm{gpm}$ (Tests 2 and Test 5), the PSDs indicated a significant number of particles with sizes less than or equal to $37 \mu \mathrm{m}$. Note those tests had the lowest flow rate of $4 \mathrm{gpm}$ per MJP. These results indicate that tests at the lower pump velocity of $4 \mathrm{gpm}$ did not result in optimum elutriation efficiency. The velocity was too low to remove all of the slow-settling particles to the receipt tank, and hence, the reason for smaller size particles remaining in the Mixing Tank. 


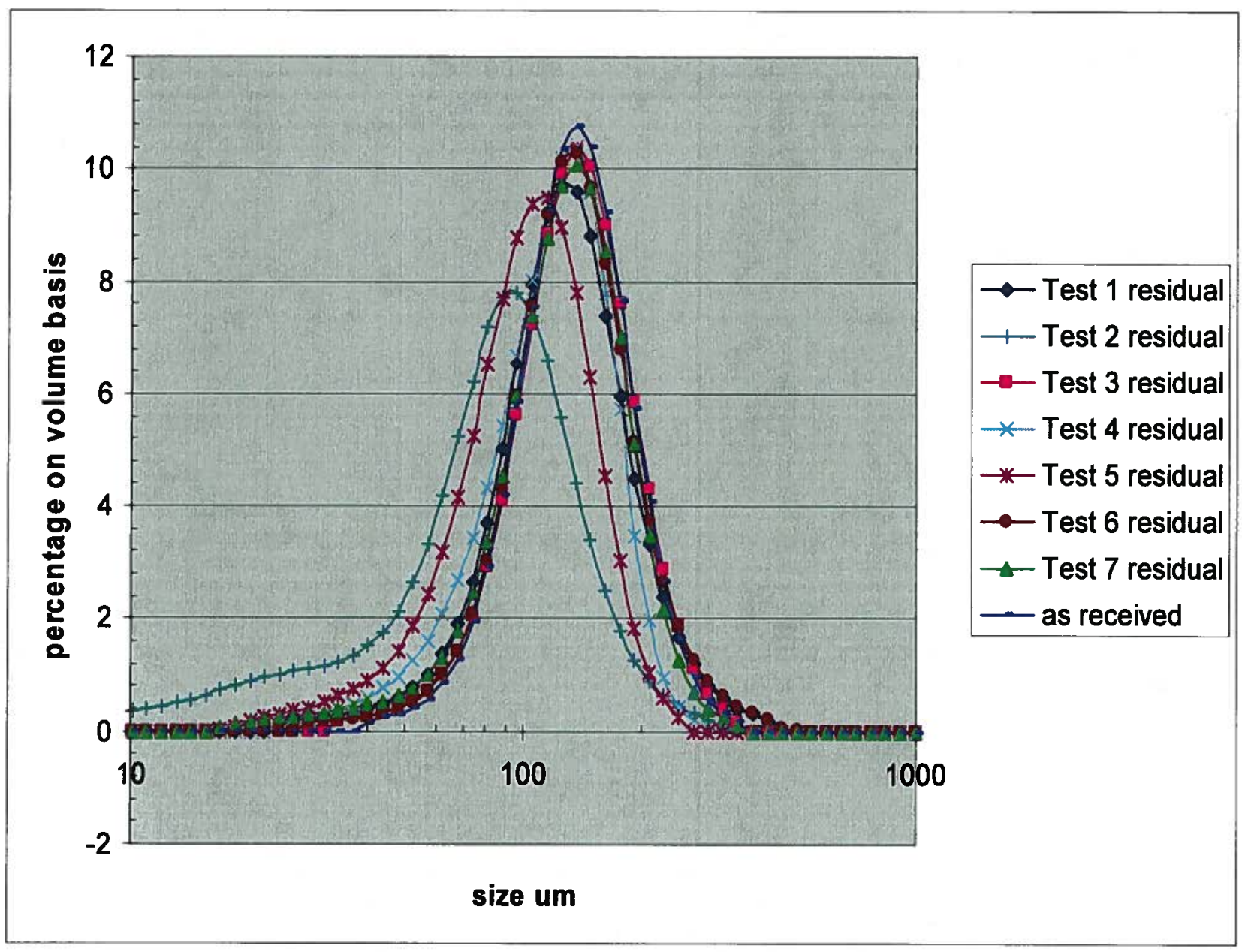

Figure 9

Particle Size Distributions for Tank Residue

Figure 10 shows the PSDs for the contents of the Receipt Tanks in Test 7. This figure shows that the PSD for Test 7 RT3 had two maxima, one at $20 \mu \mathrm{m}$ for slow-settling particles and one at 74 $\mu \mathrm{m}$ for fast-settling particles. The bimodal distributions indicate that both fast- and slow-settling particles were present. These results would be anticipated since the mixing pump flow rate was the highest tested at $8 \mathrm{gpm}$ which would have removed a large portion of both slow- and fastparticles from the MDT to the Receipt Tanks. 


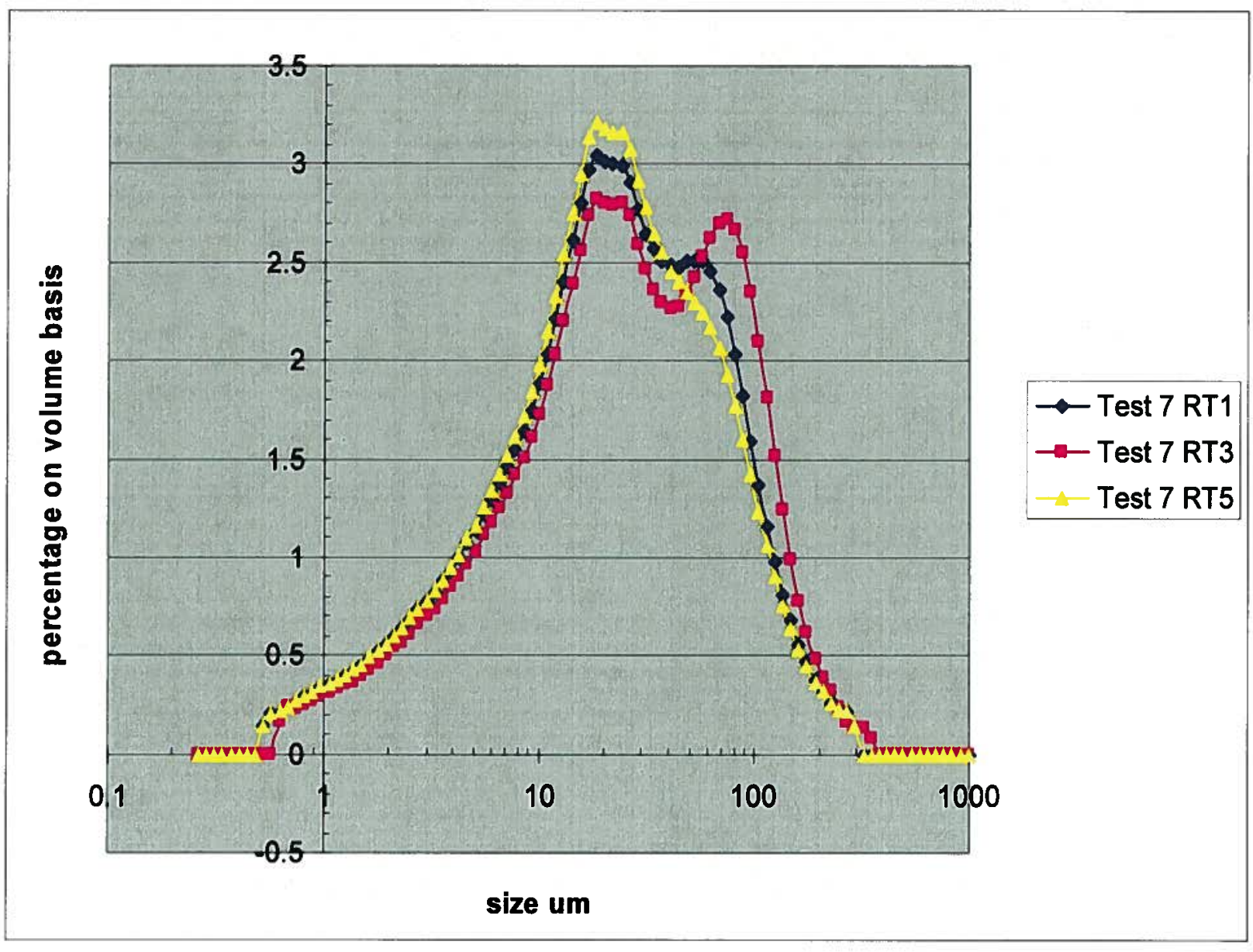

Figure $10 \quad$ Particle Size Distributions for Receipt Tanks, Test 7

\subsection{Summary of Results}

The elutriation scoping test have shown that the most significant factor that impacts separation efficiency of particles is the MJP flow rate, which is directly related to jet velocity in the vicinity of the removal tube. The jet velocity that suspends solids and allows them to be removed from the tank is the velocity of the jet in the vicinity of the removal tube. Blevins [1984] gives the maximum velocity downstream of an axisymmetric jet.

$\mathrm{U}_{\mathrm{m}}=12 \mathrm{r}_{0} \mathrm{U}_{0} / \mathrm{x}$

where $r_{0}$ is the radius of the nozzle, $U_{0}$ is the velocity at the nozzle and $x$ is the distance downstream of the nozzle. This equation was used to compute the jet velocities entered into Table 6. 
Table $6 \quad$ SRNL Elutriation Jet Velocities

\begin{tabular}{|c|c|c|c|}
\hline Test \# & Date & MJP Flow (gpm) & $\begin{array}{c}\text { Jet Velocities } \\
\text { (ft/sec) }\end{array}$ \\
\hline 1 & $9 / 1 / 2010$ & 5 & 1.89 \\
\hline 2 & $9 / 13 / 2010$ & 4 & 1.51 \\
\hline 3 & $9 / 16 / 2010$ & 6 & 2.27 \\
\hline 4 & $9 / 22 / 2010$ & 5 & 1.89 \\
\hline 5 & $9 / 27 / 2010$ & 4 & 1.51 \\
\hline 6 & $10 / 1 / 2010$ & 5 & 1.89 \\
\hline 7 & $10 / 4 / 2010$ & 8 & 3.03 \\
\hline
\end{tabular}

The goal of the elutriation scoping testing was to separate the particles leaving the fast-settling particles in the mixing tank while removing the slow-settling particles into the Receipt Tanks. The results are summarized in Figure 11 which plots the volume fraction of fast-settling particles in the tank residue and the Receipt Tanks using two measurement methods. Three significant trends were observed in Figure 11:

1. Increasing the MJP flow rate, and hence, jet velocity resulted in an increasing amount of fast-settling solids removal from the MDT into the Receipt Tanks.

2. Low pump speeds ( $4.0 \mathrm{gpm}$, jet velocity of $1.5 \mathrm{ft} / \mathrm{sec}$ ) resulted in significant amounts of slow-settling solids remaining in the MDT. Figure 10 illustrates this by the percentage of fast-settling solids remaining in the $\mathrm{MDT}$ decreasing from the near $100 \%$ shown in runs at higher pump flow rates to an approximate $80 \%$.

3. An optimum MJP flow rate of $5.0 \mathrm{gpm}$ (jet velocity of $1.89 \mathrm{ft} / \mathrm{sec}$ ) resulted in the minimum amount of heavy fast-settling particles from being entrained into the Receipt Tanks and the maximum amount of lighter slow-settling particles being separated into the RTs. 


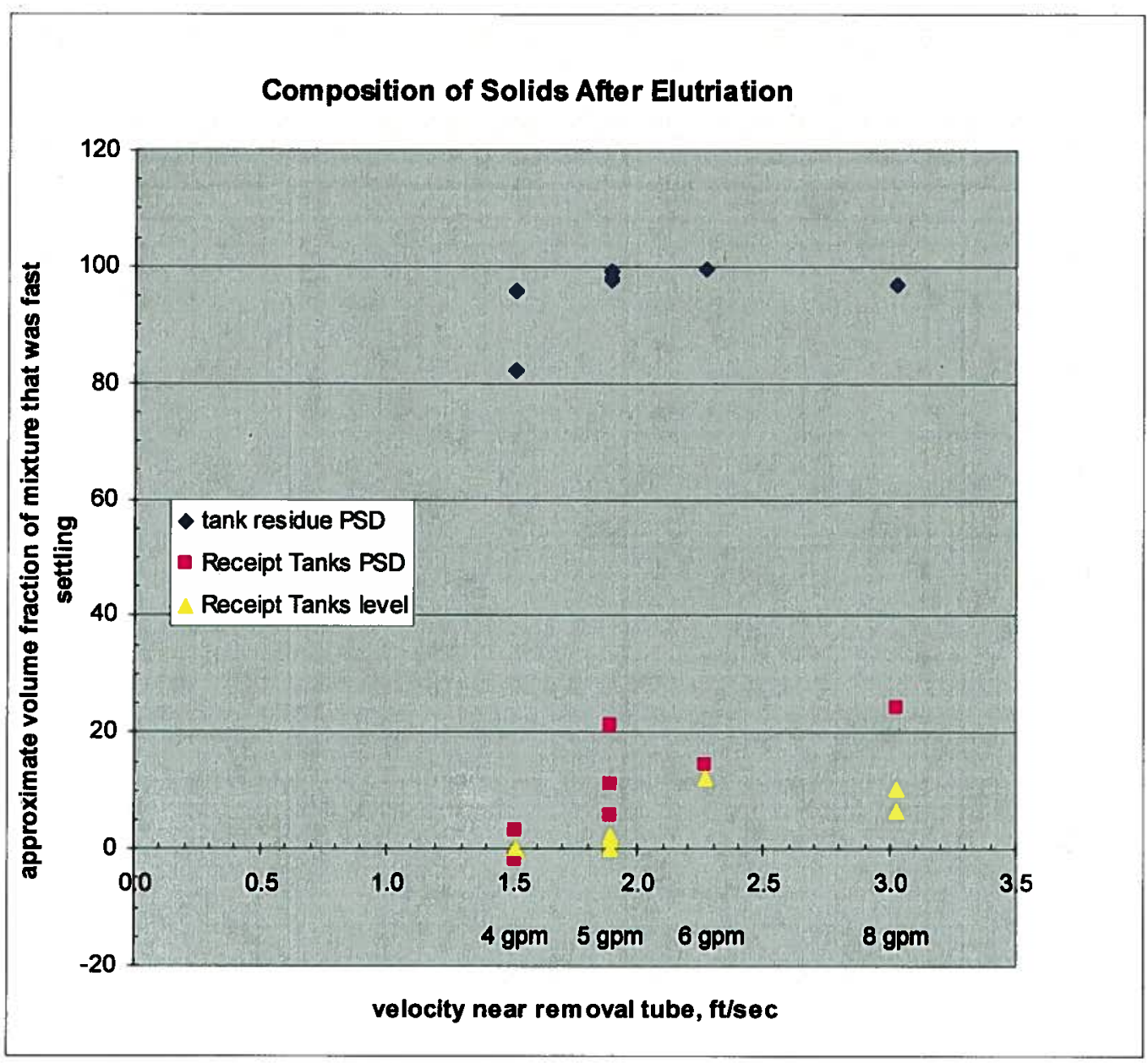

Figure 11 Trends - Increasing Fast-Settling Solids in Receipt Tanks with Increasing

\subsection{Calculation of Data in Figure 11}

The fraction of fast-settling particles in the Receipt Tanks was calculated two ways. The first way was to divide the volume of fast-settling particles listed in Table 5 by the total particle volume. The results are plotted in Figure 11 . Increasing velocity generally increases the fraction of the contents of the Receipt Tanks that is fast-settling particles.

The second way that fraction fast-settling particles was calculated was more complicated and based on PSDs. Figure 10 shows that the PSD for Test 7 RT3 had two maxima, one at $20 \mu \mathrm{m}$ for slow-settling particles and one at $74 \mu \mathrm{m}$ for fast-settling-particles. Ideally the Receipt Tanks would contain $100 \%$ slow-settling particles with no fast-settling particles. The following steps were used to estimate the fraction of fast-settling particles in the Receipt Tanks. The slowsettling PSD in Figure 9 was integrated from $74 \mu \mathrm{m}$ to $1000 \mu \mathrm{m}$. The same integration was performed for the PSDs for the contents of the Receipt Tanks for the seven tests. In each case the fast-settling PSD integral was subtracted from the Receipt Tank integral to give an estimate of what fraction of fast-settling particles larger than $74 \mu \mathrm{m}$ was in the Receipt Tank. The PSD for fast-settling particles is approximately symmetrical so the volume of fast-settling particles less than $74 \mu \mathrm{m}$ is equal to the volume greater than $74 \mu \mathrm{m}$. Therefore, the amounts of fast-settling particles greater than $74 \mu \mathrm{m}$ were doubled to get the total amount of fast-settling particles. The 
results are plotted in Figure 11 as a function of velocity in the vicinity of the removal tube. The contents of the Receipt Tanks contained almost no fast-settling particles for a velocity of 1.5 $\mathrm{ft} / \mathrm{sec}$ and increasing amounts of fast-settling particles for velocities of $1.9 \mathrm{ft} / \mathrm{sec}$ and greater. The two methods for computing the fraction of fast-settling particles in the Receipt Tanks give different absolute values, but the same trends.

PSDs were also used to estimate the fraction of slow-settling particles in the mixing tank residue. Figure 8 shows that none of the as-received fast-settling particles had a size of $37 \mu \mathrm{m}$ or less. Figure 9 shows that some of the PSDs for the residues in the tank had significant numbers of particles smaller than $37 \mu \mathrm{m}$ as the result of admixture of slow-settling particles. Ideally the residue would be $100 \%$ fast-settling particles with no slow-settling particles. The following steps were used to estimate the fraction of slow-settling particles in the residues. The PSD for slowsettling particles in Figure 8 was integrated from zero to $37 \mu \mathrm{m}$ and it was determined that $83 \%$ of the total volume of slow-settling particles had a size of $37 \mu \mathrm{m}$ or less. Then each of the PSDs for residues plotted in Figure 9 was integrated from zero to $37 \mu \mathrm{m}$ to give the fraction of total volume that was less than or equal to $37 \mu \mathrm{m}$. That fraction was divided by 0.83 to get an estimate of the fraction of slow-settling particles in the sample. The results are plotted in Figure 11 as a function of jet velocity in the vicinity of the removal tube. The residue contained a significant amount of slow-settling particles for a jet velocity of $1.5 \mathrm{ft} / \mathrm{sec}$ and little slow-settling particles for velocities of $1.9 \mathrm{ft} / \mathrm{sec}$ or greater.

Table $7 \quad$ Elutriation Tests Data Summary

\begin{tabular}{|c|c|c|c|c|c|c|c|}
\hline Test \# & Date & $\begin{array}{c}\text { MJP } \\
\text { Flow } \\
\text { (gpm) }\end{array}$ & $\begin{array}{c}\text { Residue } \\
\leq \mathbf{3 7} \mathbf{~ u m}\end{array}$ & $\begin{array}{c}\text { \% } \\
\text { Gibbsite } \\
\text { in } \\
\text { Residue }\end{array}$ & $\begin{array}{c}\text { Receipt } \\
\text { Tank 1 } \\
\geq 74 \text { um }\end{array}$ & $\begin{array}{c}\text { Receipt } \\
\text { Tank 3 } \\
\geq 74 \text { um }\end{array}$ & $\begin{array}{c}\text { Receipt } \\
\text { Tank 5 } \\
\geq 74 \text { um }\end{array}$ \\
\hline 1 & $9 / 1 / 2010$ & 5 & 1.48 & 98.21 & 22.00 & 14.90 & 8.70 \\
\hline 2 & $9 / 13 / 2010$ & 4 & 14.60 & 82.33 & 7.80 & 6.10 & 4.60 \\
\hline 3 & $9 / 16 / 2010$ & 6 & 0.41 & 99.50 & 9.30 & 12.80 & 13.60 \\
\hline 4 & $9 / 22 / 2010$ & 5 & 1.82 & 97.80 & 6.30 & 7.50 & 8.50 \\
\hline 5 & $9 / 27 / 2010$ & 4 & 3.49 & 95.78 & 4.60 & 5.20 & 1.20 \\
\hline 6 & $10 / 1 / 2010$ & 5 & 0.74 & 99.10 & 10.60 & 10.30 & 9.30 \\
\hline 7 & $10 / 4 / 2010$ & 8 & 2.57 & 96.89 & 15.20 & 21.30 & 13.80 \\
\hline
\end{tabular}

Newitt, et al. [1955] measured velocities in pipe that were necessary to just suspend sand and gravel off the bottom of the pipe with a water flow. The velocity to just suspend $100 \mu \mathrm{m}$ sand was $2 \mathrm{ft} / \mathrm{sec}$. This is approximately consistent with the velocity that suspends significant quantities of stainless steel which results in stainless steel being transported to the Receipt Tanks. 


\subsection{Conclusions and Recommendations for Path Forward}

The successful In-tank Elutriation in Hanford Tank S-112 and the successful Phase 1 elutriation tests at SRNL show that the concept has potential to significantly reduce the cost of tank closure. The testing and previous results were related to Salt Waste tanks; however, benefits of elutriation could be shown to be applicable to Sludge Waste tanks as well. There were certain limitations to the simulant used in the elutriation testing performed at SRNL, specifically with the magnetic effects of the stainless steel materials, however, the proof of concept was evident in the testing. The development of the concept will require additional work, listed below.

1. Elutriation of Tank S-112 required large quantities of $50 \mathrm{wt} \%$ caustic to break up the hard cobble in that salt waste tank. The consequences of adding large quantities of caustic to other tanks should be analyzed. Addition of caustic impacts tank space and will require additional evaporation. Another consideration in elutriation is that washing of solids will be required to remove phosphate and oxalate, which would otherwise precipitate with the caustic treatment.

2. In-Tank Elutriation was shown at Hanford to be useful in salt waste tanks, and successful implementation of elutriation required preliminary steps, which have costs associated with them. The preliminary steps are removal of soluble salts, breaking up hard salt pan, and digesting cobble to sand using caustic solution. Since the salt waste tanks probably can not be heated, this probably means treatment with stronger than $25 \%$ caustic, although perhaps not $50 \%$. Therefore, a cost and benefit analysis should be performed. The ability to leave more innocuous gibbsite in a waste tank has benefits, but the introduction of large quantities of caustic into the waste stream has costs. The cost and benefit analysis should also consider how many tanks could use elutriation.

3. Laboratory analysis of actual tank waste solids is critical in evaluating the efficacy of elutriation for a waste tank (including sludge waste tanks). Tank waste samples are archived in the Hanford 222-S Laboratory and are available for analyses. There are two types of analyses that are needed to develop a representative simulant:

a. Solids Density and Size Measurement - Based on chemical and physical analyses of the waste solids, determine whether elutriation is likely to be possible by calculation of the settling velocities of the solids by first measuring the solid density and size.

b. Volume Fraction of Solids -For use in waste tanks, develop a representative simulant by closely matching the volume fractions of fast-settling and slow-settling particles if data is available from tank characterization.

If after evaluating the settling velocities and elutriation is considered possible, then a representative sample can be generated and elutriation testing performed.

4. Perform testing with a hydrocyclone in a scaled test with the representative simulant. Hydrocyclones have the potential to further separate tank solids that have been elutriated from the tank with less required liquid.

5. Research whether leaving larger quantities of sandy material in a waste tank will compromise the integrity of tank grouting. 


\subsection{References}

Adamson, D. J, Poirier, M. R. and Steeper, T.J., "Demonstration of Simulated Waste Transfers From Tank AY-102 to the Hanford Waste Treatment Facility", SRNL-STI-2009-00717, November 2009.

Adamson, D. J., “In-Tank Elutriation”, SRNL-NB-2010-00129.

Adamson, D. J., "In-Tank Elutriation Proof of Concept Testing", R \& D Direction, Sept. 1, 2010.

Adamson, D. J., Restivo, M. L., Steeper, T. J., Greer, D. A., "Demonstration of Mixer Jet Pump Rotational Sensitivity on Mixing and Transfer of the AY-102 Tank", SRNL-STI-2010-00521, Sept. 2010.

Barton, W. B., "Caustic Cleaning for Waste Tank Heel Removal”, Waste Processing Technical Exchange, Denver, May 19, 2009.

Cantrell, et al, "Hanford Tank 241-S-112 Residual Waste Composition and Leach Test Data", PNNL-17593, 2008.

Dodd, R. A., "Tank Waste Retrieval Lessons Learned at the Hanford Site", International Waste Management Conference, Phoenix AZ, 2008.

Duignan, M. R., "Final Report: DWPF Glass Frit and Water Separation Test", WSRC-TR-98$00107,1998$.

Eacker, J. A., Thompson, W. T., Gibbons, P. W., "Retrieval of Hanford's Single Shell Nuclear Waste Tanks Using Technologies Foreign and Domestic", WM'03 Conference, Feb. 23-27, 2003, Tucson, AZ.

Kirk Othmer Encyclopedia of Chemical Technology, article on Separation, Size, $5^{\text {th }}$ edition, 2006.

National Research Council, "Tank Waste Retrieval, Processing and On-Site Disposal at Three Department of Energy Sites", National Academies Press, 2006.

Newitt, D. M, Richardson, J. F., Abbott, M., and Turtle, R. B., "Hydraulic Conveying of Solids in Horizontal Pipes", Trans. Instn. Chem. Engrs., Vol. 35, pp. 93-113, 1955. 


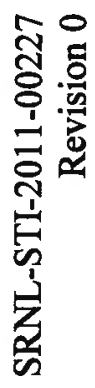

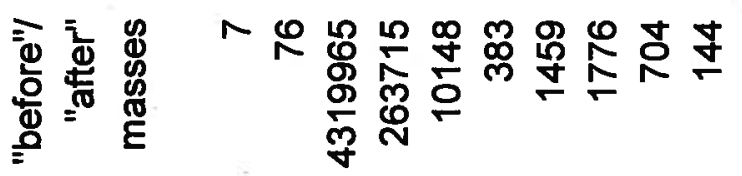

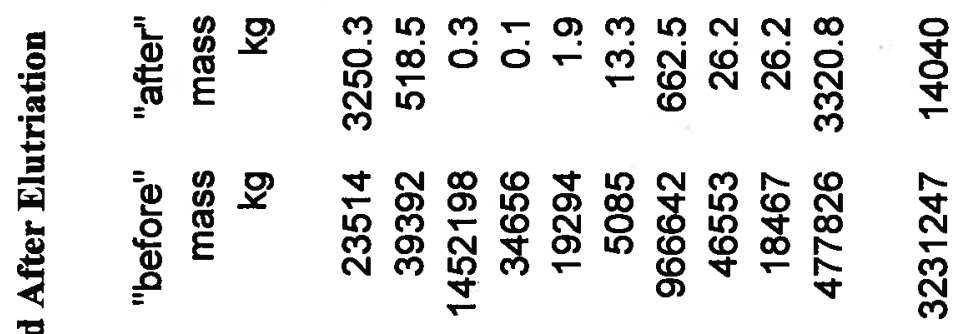

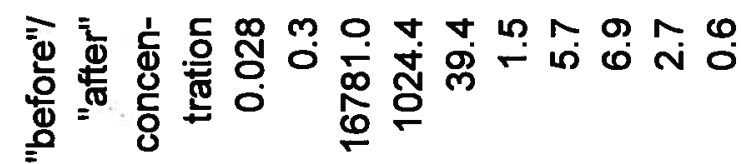

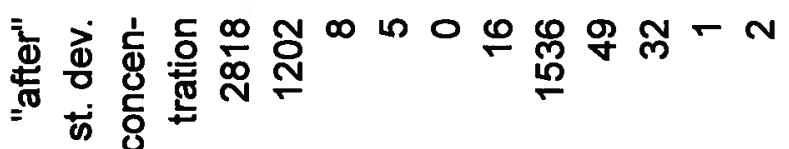

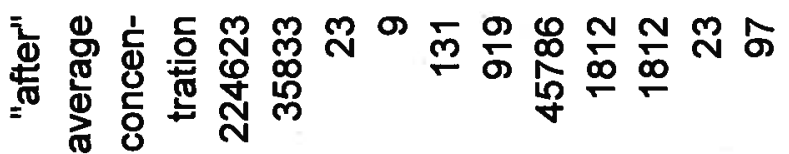

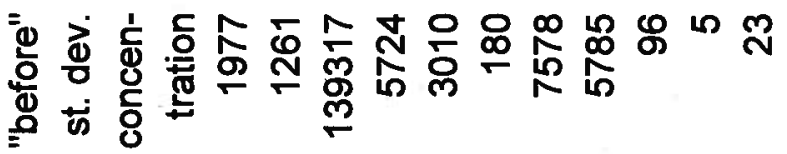

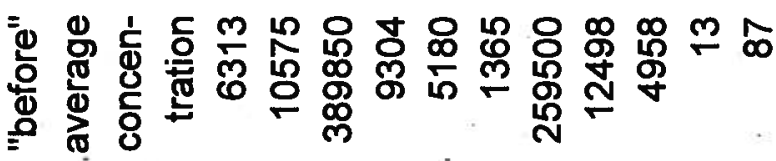

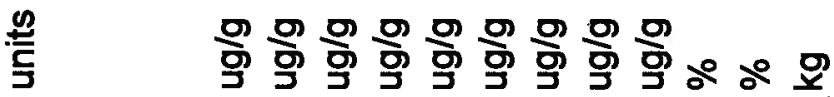

$\frac{\mathscr{\Phi}}{\mathbb{\$}}$

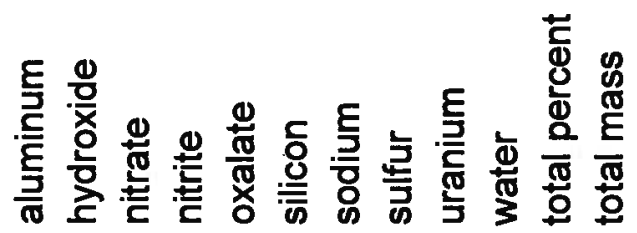




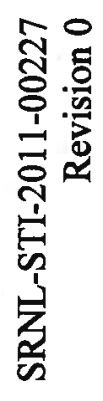

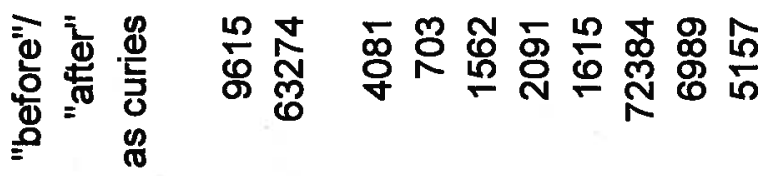

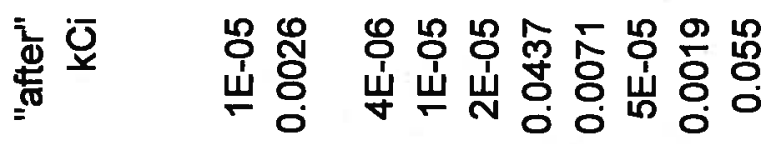

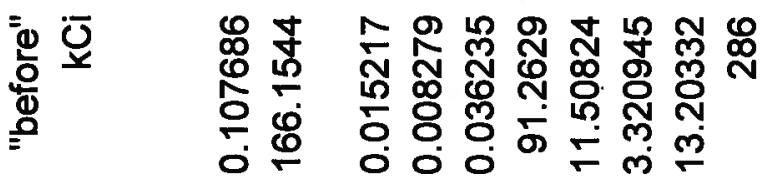

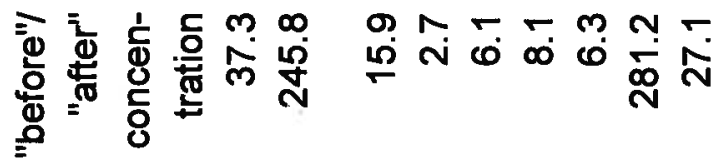

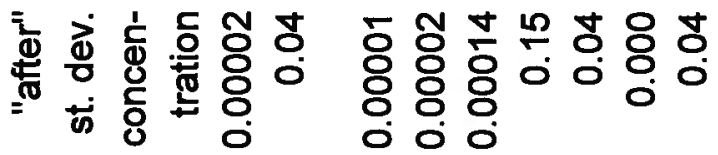

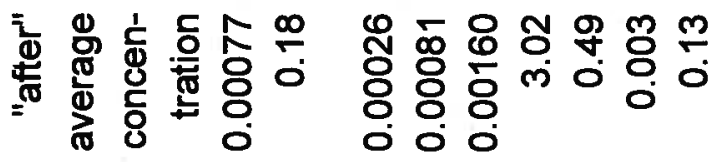

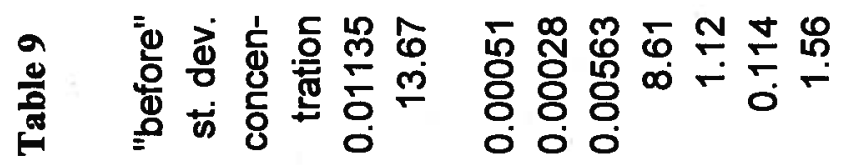

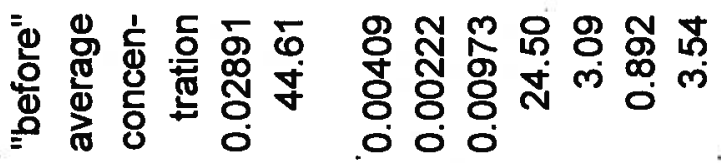

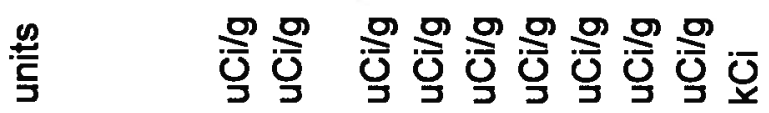

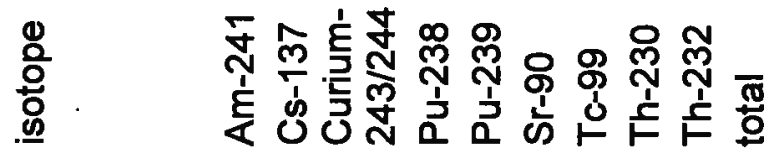


Distribution:
A. B. Barnes, 999-W
D. A. Crowley, 773-43A
S. D. Fink, 773-A
B. J. Giddings, 786-5A
C. C. Herman, 999-W
S. L. Marra, 773-A
F. M. Pennebaker, 773-42A
J. H. Scogin, 773-A
W. R. Wilmarth, 773-A
H. H. Burns, 773-41A 